\title{
Splenic Capture and In Vivo Intracellular Biodegradation of Biological-Grade Graphene Oxide Sheets
}

\author{
Leon Newman," Dhifaf A. Jasim,, Eric Prestat, Neus Lozano, Irene de Lazaro, Yein Nam, Bakri M. Assas, \\ Joanne Pennock, Sarah J. Haigh, Cyrill Bussy,* and Kostas Kostarelos*
}

Cite This: ACS Nano 2020, 14, 10168-10186

Read Online

ACCESS | 페 Metrics \& More | 回 Article Recommendations

ABSTRACT: Carbon nanomaterials, including 2D graphenebased materials, have shown promising applicability to drug delivery, tissue engineering, diagnostics, and various other biomedical areas. However, to exploit the benefits of these materials in some of the areas mentioned, it is necessary to understand their possible toxicological implications and longterm fate in vivo. We previously demonstrated that following intravenous administration, 2D graphene oxide (GO) nanosheets were largely excreted via the kidneys; however, a small but significant portion of the material was sequestered in the spleen. Herein, we interrogate the potential consequences of this accumulation and the fate of the spleen-residing GO over a

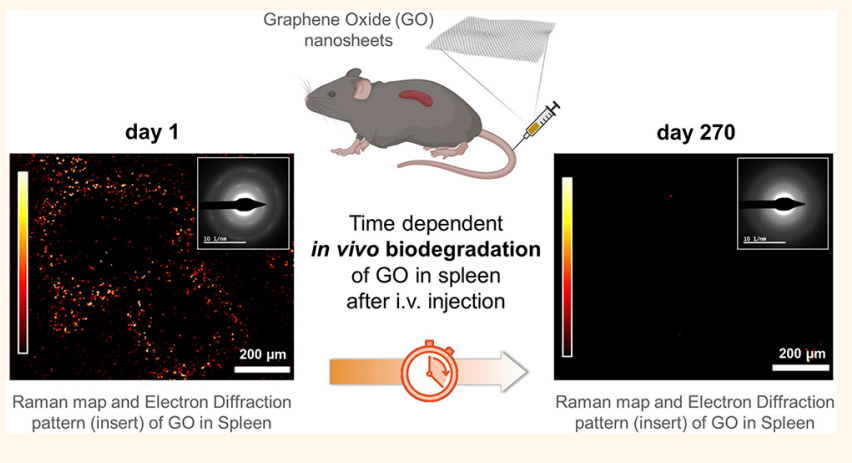
period of nine months. We show that our thoroughly characterized GO materials are not associated with any detectable pathological consequences in the spleen. Using confocal Raman mapping of tissue sections, we determine the sub-organ biodistribution of GO at various time points after administration. The cells largely responsible for taking up the material are confirmed using immunohistochemistry coupled with Raman spectroscopy, and transmission electron microscopy (TEM). This combination of techniques identified cells of the splenic marginal zone as the main site of GO bioaccumulation. In addition, through analyses using both bright-field TEM coupled with electron diffraction and Raman spectroscopy, we reveal direct evidence of in vivo intracellular biodegradation of GO sheets with ultrastructural precision. This work offers critical information about biological processing and degradation of thin GO sheets by normal mammalian tissue, indicating that further development and exploitation of GO in biomedicine would be possible.

KEYWORDS: 2D materials, degradation, macrophage, toxicology, nanomedicine

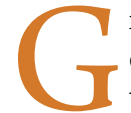

raphene-based materials (GBMs) have potential for exciting applications including those related to medical technologies, such as improved drug delivery. ${ }^{1-4}$ A key concern, however, is the implications of interactions of these engineered nanomaterials with the mammalian biological milieu. ${ }^{5}$ Understanding the fate of GBMs after administration to the body and the materials' tendencies to accumulate within organs and cells, especially those of the mononuclear phagocytic system (MPS), such as the lungs, liver and spleen, and the effects thereof, ${ }^{6,7}$ are key in defining whether GBMs will be suitable for biomedical applications.

Preferential accumulation of nanomaterials in one component of the MPS over another is typically influenced by the route of administration and the physicochemical characteristics of the materials administered. ${ }^{8} \mathrm{We}$ and others have reported the accumulation of functionalized GBMs in the spleen following intravenous (i.v.) $)^{6,9}$ and intraperitoneal administration. ${ }^{7}$ Splenic accumulation after i.v. administration is not restrictive only to GBMs; ${ }^{6}$ it has been reported for various other nanomaterials. ${ }^{10,11}$ In terms of physicochemical characteristics, we showed that thicker GBMs such as multilayer graphene oxide (GO) sheets are more likely to be trapped within the capillary beds of the lungs compared with single-to-few-layer GO sheets, after systemic administration. ${ }^{12}$ Single-to-few-layer GO sheets, on the other hand, have a greater capacity to be excreted via the urinary tract and for the small fraction of this material that remained in

Received: April 24, 2020

Accepted: July 13, 2020

Published: July 13, 2020 
ब

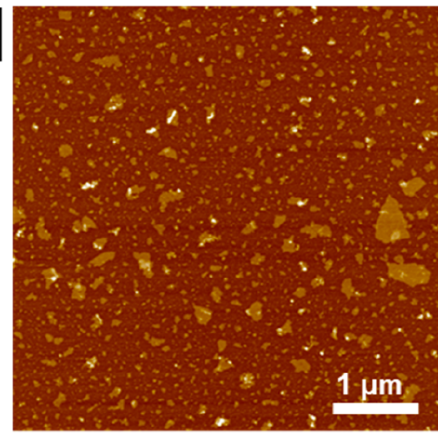

B

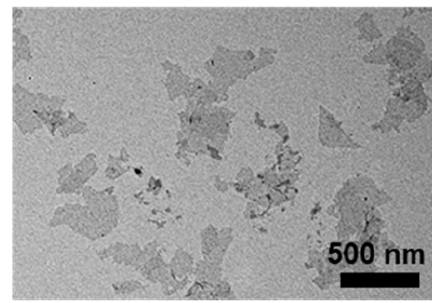

$5 \mathrm{~nm}$
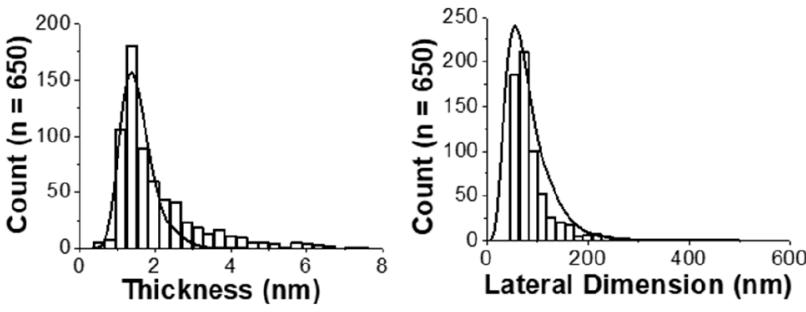

D

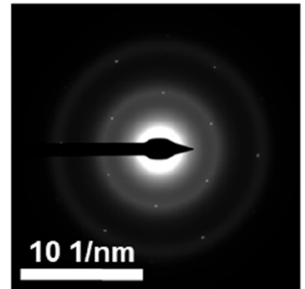

Figure 1. Physicochemical characterization of GO, prior to injection. (a) AFM image, with corresponding graphs showing the distribution of sheet thickness and lateral dimensions. (b) TEM. (c) Raman spectroscopy with $I(D) / I(G)$ ratio. (d) Electron diffraction pattern with the corresponding SAED aperture micrograph given in Figure S1. Further physicochemical characterization is shown in Figure S2.

the body, this was shown to accumulate predominantly within the spleen. 9,12

The spleen is a highly specialized organ; it forms a major part of the MPS and has major functions in the innate and adaptive branches of the immune system. ${ }^{13}$ It is adapted to filtering blood via the strategic placement of an array of phagocytic cells, such as specialized macrophages. These phagocytic cells act to "clean" the blood of foreign-body invaders and particulates. The filtered blood is then returned to the main circulation via the efferent splenic vein. ${ }^{13}$ The spleen also contains large numbers of lymphoid cells and antigen-presenting cells, such as dendritic cells. If foreign-body invaders or particulates, such as GBMs, are recognized by these cells as antigens, they may induce antigenspecific immune responses. ${ }^{14,15}$ Besides immune-related functions, the spleen also plays an important role in the maintenance of a healthy red blood cell (RBC) population and the storage of iron. $^{13}$

Accumulation of GBMs within the spleen following administration has been reported to be without toxicological consequences. ${ }^{7}$ At the same time, however, various reports have detailed extensive immune responses characterized by upregulation of inflammatory markers as well as histopathological changes $^{6}$ following the administration of GBMs. Such discrepancies are often linked to the inhomogeneity in physicochemical properties, such as thickness, lateral dimensions, and levels of surface functionalization, of the administered GBMs between investigations. ${ }^{8,16}$ Thick, large, or poorly functionalized sheets are more likely to have detrimental consequences compared with thin, small, well-functionalized, and highly dispersed materials. Variations in GBM characteristics can, therefore, determine the impact of the materials on biological systems ${ }^{8}$ and consequently affect its applicability in biomedical research particularly with regard to systemic drug delivery.

GO sheets are a promising class of GBMs that have been investigated extensively in biomedicine; like other GBMs, they are often complex and poorly characterized, leading to discrepancies in the literature in terms of toxicology. One aspect that is particularly sensitive to variations in physicochemical characteristics is the in vivo long-term fate and, in particular, the biodegradability of the materials. ${ }^{5,17,18}$

The degradability of $\mathrm{GO}$, as well as related carbon nanomaterials, has been reported in the literature under different conditions mimicking biological processes. Various studies describe degradative processes mediated by oxidizing chemicals, ${ }^{19-22}$ as well as free radicals (reactive oxygen species or reactive nitrogen species) generating enzymes, including some that are relevant to mammals. ${ }^{17,18,23-26}$ Such studies have suggested that the colloidal characteristics of GO dispersions, and the material characteristics that control these, are important determinants of the biodegradability of the materials. ${ }^{17}$ Low levels of surface functionalization and increased thickness are, for instance, likely to promote poor dispersibility and aggregation/agglomeration of the materials, thereby hindering their enzyme-mediated biodegradation; the contrary would promote it. ${ }^{17,18}$ However, these studies provide limited information as to the potential of GBMs to degrade in vivo.

In this respect, the most advanced study so far describes the biodegradability of carboxylated graphene (GO-like materials) over a period of three months in mice, using confocal Raman spectroscopy. ${ }^{6}$ The authors reported the continuing but incomplete biodegradation of thick graphene-based aggregates in different organs of the MPS with ensuing development of associated pathological features. ${ }^{6}$ Noticeably, the spleen was shown to degrade the accumulated material at a faster rate compared with other components of the MPS. ${ }^{6}$

In order to develop $\mathrm{GO}$ as a potential vehicle for therapeutics or diagnostics, more work is required to determine the exact degree of biodegradability of these materials in vivo. In previous reports, we demonstrated that after i.v. administration, single-tofew-layer GO sheets are largely excreted via the kidneys and urinary tract. ${ }^{9,27}$ We quantified the amount of material excreted as well as that retained in the body and examined the interaction of $\mathrm{GO}$ with the kidneys and its toxicological consequences. ${ }^{27}$ Importantly, we showed that a small, yet significant, proportion of this thin material was sequestered within the spleen. Herein, 
A
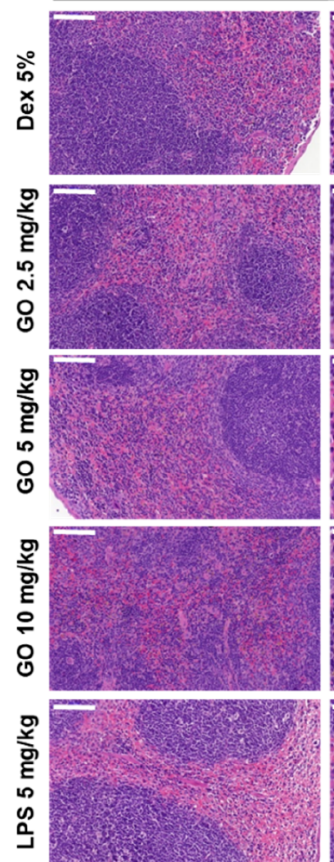

B
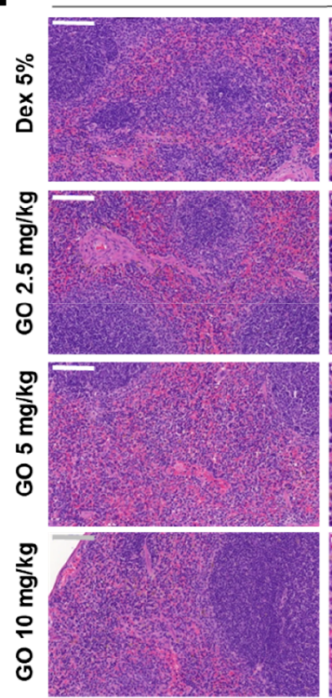

$24 \mathrm{~h}$
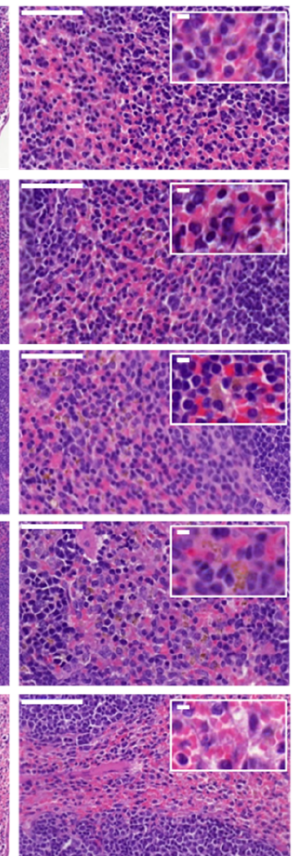

1 month
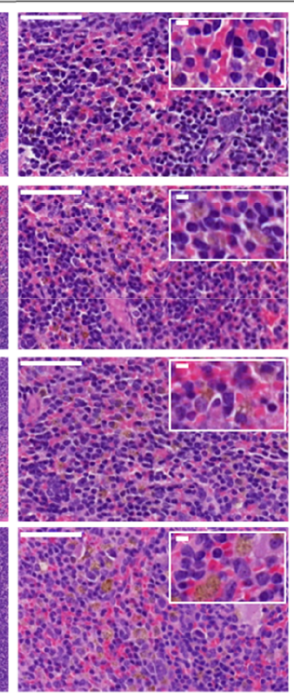
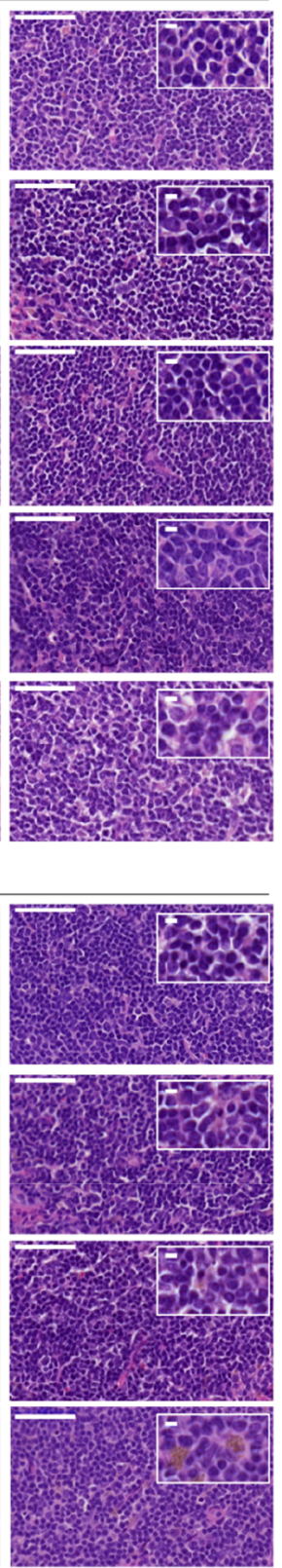

c

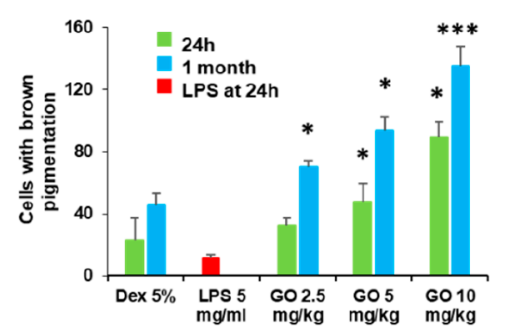

Figure 2. Effect of GO on spleen structure. H \& E-stained spleen sections ( $5 \mu \mathrm{m}$ thick) are shown after injection of GO $(2.5,5$, and $10 \mathrm{mg} / \mathrm{kg})$, Dex $5 \%$ (negative control), and LPS $5 \mathrm{mg} / \mathrm{kg}$ (positive control) after (a) $24 \mathrm{~h}$ and (b) one month postinjection. The first column is composed of 20X magnification images. Scale bars represent $100 \mu \mathrm{m}$. The middle and last columns show $60 \times$ magnifications of red and white pulps, respectively. The scale bars represent $50 \mu \mathrm{m}$. The inset images show $300 \times$ magnified regions with scale bars that represent $5 \mu \mathrm{m}$. (c) Quantification of the total cells with brown pigmentation detected in spleen sections. Data are represented as mean \pm standard error (SE). Statistical significance was assessed via the Kruskal-Wallis multiple comparison test and Dunns' posthoc test $\left({ }^{*} p<0.05, * * * p<0.005 v s\right.$ agematched negative control). There were $n=3-4$ mice per group.

we build on these previous findings and report a much-needed long-term study investigating both the impact and in vivo biodegradability of the portion of the small and thin GO sheets sequestered within the spleen over nine months following i.v. administration in mice.

\section{RESULTS AND DISCUSSION}

Two criteria are preferable in the development of engineered nanomaterials for biomedical applications: a safe in vivo profile in the context of the designated application and the capacity for effective, or controlled, biodegradation or body elimination. ${ }^{5}$
Among GBMs, GO sheets are the most studied oxidized derivatives of $\mathrm{sp}^{2}$-hybridized carbon nanomaterials for biomedical applications. This is due to their relatively hydrophilic nature and amenability to surface functionalization. ${ }^{28}$ These features give GO sheets a strong capacity particularly regarding the design of two-dimensional nanoscale carriers for drugs and other pharmaceutical agents. ${ }^{2,29,30}$ However, information concerning the in vivo safety profile and fate over time of GO sheets is limited. ${ }^{5}$ Considering our previous study, which demonstrated that the spleen is the primary organ of accumulation of the GO dose fraction not excreted via the 
kidney after i.v. administration in mice, ${ }^{9}$ the primary objective of the present study was to understand the impact of this accumulation on the spleen structure and function and to reveal the in vivo fate (i.e., biodegradability) of the GO sequestered within the spleen.

\section{BIOLOGICAL-GRADE GO SHEETS HAVE IDEAL FEATURES FOR BIOMEDICAL STUDIES}

Various reports have detailed the importance of properly defining and characterizing GBMs in biomedical research. ${ }^{5,16,31}$ Characteristics such as lateral dimensions, thickness, and surface functionalization are key determinants of the impact of GBMs on biological systems. ${ }^{8}$ Following the production of an aqueous GO suspension, an extensive physicochemical characterization of the GO sheets was performed. First, atomic force microscopy (AFM) and transmission electron microscopy (TEM) were used to confirm the synthesis of single-to-few-layer GO sheets with lateral dimensions below $2 \mu \mathrm{m}$ with a log-normal distribution (Figure $1 \mathrm{~A}$ and B). Previous studies recommend that when injecting colloidal particles intravenously, the material dimensions should not exceed the diameter of a capillary (5-7 $\mu \mathrm{m}){ }^{32}$ This is because the materials must be able to journey through these narrow blood vessels following administration without getting trapped, for example, in the lung capillary bed. ${ }^{8,32,33}$

Spectroscopic analysis was then performed and consistent with that expected of GO: an $s p^{2}$-hybridized carbon hexagonal lattice interspersed with oxygen functionalities. Raman spectroscopy showed enhanced scattering in the $\mathrm{D}$ band relative to the $\mathrm{G}$ band (Figure $1 \mathrm{C}$ ), which indicated the presence of defects within the graphitic backbone of GO. This finding was corroborated by the hexagonal electron-diffraction pattern, which showed diffusivity within the diffraction rings, suggestive of the presence of crystalline and noncrystalline regions within the GO sheets (Figure 1D). The corresponding electron micrograph is provided in Figure S1. Attenuated total reflectance Fourier-transform infrared spectroscopy (ATR FTIR) indicated that these defective regions were occupied by various oxygen-containing functional groups (Figure S2A). For instance, stretching vibrations of the $\mathrm{O}-\mathrm{H}$ bond were observed as a broad band between 3000 and $3700 \mathrm{~cm}^{-1}$; $^{34}$ these likely originated from hydroxyl and carboxyl groups and residual tightly bound water molecules. Aliphatic $\mathrm{C}-\mathrm{H}$ stretching vibrations were observed as a minor band around 2815 $\mathrm{cm}^{-1,35}$ while stretching vibrations originating potentially from $\mathrm{C}=\mathrm{O}$ groups, present in carbonyl and carboxyl groups, were demonstrated by a sharp peak at approximately $1725 \mathrm{~cm}^{-1}$. 28,34 Evidence of in-plane vibrations in cyclic aromatic networks were also observed as very weak bands between 1500 and 1600 $\mathrm{cm}^{-1}, 28,36$ although, $\mathrm{O}-\mathrm{H}$ bending modes in adsorbed water molecules, expected around $1625 \mathrm{~cm}^{-1}$, may have also contributed. $^{28,37}$ Bending vibrations of $\mathrm{O}-\mathrm{H}$ present in hydroxyls were detectable as a strong band around 1400 $\mathrm{cm}^{-1} \cdot{ }^{28,37}$ Evidence of ether groups could also be detected; they have previously been reported to result in intense absorption bands around 1045 and $965 \mathrm{~cm}^{-1}$, which correspond to C-O stretching vibrations; ${ }^{28,34}$ epoxides may finally have contributed to vibrations around $850 \mathrm{~cm}^{-1}$. ${ }^{28}$ These inferences were supported by thermogravimetric analysis (TGA) (Figure S2B) and X-ray photoelectron spectroscopy (XPS) (Figure S2C-i and $\mathrm{C}$-ii) data. TGA data also indicated that these defected regions, occupied by oxygen-containing functionalities, constituted about $40 \% \mathrm{w} / \mathrm{w}$ of total GO. Ultraviolet-visible (UV-vis)
(Figure S2D) and fluorescence (Figure S2E) spectroscopies further revealed characteristic absorption and fluorescence curves expected for GO.

Polar oxygen-containing functionalities, as detected on our GO material, are known to minimize the thermodynamic consequences of hosting hydrophobic carbon-based materials in the hydrogen-bonding network of aqueous environments. ${ }^{38}$ In our case, this allowed the formulation of a well-dispersed GO aqueous preparation. Overall, the characterization results demonstrate the successful preparation of colloidal dispersions of GO nanosheets suitable for i.v. administration. ${ }^{8,33}$ Based on the literature and our previous work, small, well-dispersed, and thin GO sheets are less likely to cause adverse reactions due to physical entrapment in capillaries and other small blood vessels. ${ }^{12}$ Small, well-dispersed sheets are also more likely to be excreted via the kidneys and urinary tract, ${ }^{12}$ and regarding the small portion of material that remains within the body, these have a greater chance of interacting with cells without causing damage. $^{39}$

\section{GO SHEETS HAVE LIMITED EFFECT ON SPLEEN HISTOPATHOLOGY}

Following characterization and confirmation that the GO sheets were of small lateral dimensions, single-to-few layers, and extensively surface oxidized, dispersed material was administrated to mice via i.v. injection. Based on the material physicochemical features, the GO sheets were expected to accumulate over time in the spleen, as previously reported by us ${ }^{9}$ and others ${ }^{7,40}$ independently. However, we could not find any study that examined the consequences of GO accumulation on the splenic structure or function at the administered doses used here $(2.5,5 \text {, or } 10 \mathrm{mg} / \mathrm{kg})^{9,27}$

This prompted us to explore the possible effects of the accumulated material, first on spleen histology. Using H \& E staining, we observed no histopathological changes or tissue damages at either $24 \mathrm{~h}$ (Figure 2A) or one month (Figure 2B) after GO administration at doses of $2.5,5$, or $10 \mathrm{mg} / \mathrm{kg}$. Magnified regions of both red and white pulps were histologically normal in GO-injected mice and showed no apparent difference compared with those of mice injected with the vehicle control, namely, dextrose 5\% (Dex 5\%, negative control). In contrast, mice injected with bacterial lipopolysaccharide $5 \mathrm{mg} / \mathrm{kg}$ (LPS, positive control; used widely to study acute toxicological responses) $)^{41}$ exhibited a reduction in the extent of hematoxylin staining, especially in the red pulp, which is indicative of cell death. These findings were consistent with other reports, ${ }^{7}$ although some have demonstrated GO-induced structural changes associated with significant pathological implications. ${ }^{42}$ Differences in observations between studies are thought to be due to differences in the physicochemical characteristics of the GBMs used, particularly thickness, lateral dimensions, and dispersibility.

In addition to a normal histological appearance of the spleen, we observed that with increasing doses of GO $(2.5,5$, or $10 \mathrm{mg} /$ $\mathrm{kg}$ ), there was an increase in the number of individual cells showing brown pigmentation in comparison to the controls (insets in Figure 2A $(24 \mathrm{~h})$ and 2B (1 month)). All cells that visually appeared brown were counted (Figure $2 \mathrm{C}$ ), with no specific exclusion criteria applied to reduce bias. At $24 \mathrm{~h}$ after GO administration, increase in pigmentation was particularly apparent in the red pulp and marginal zone regions of the spleen. This increase in pigmentation in GO-treated animals compared with controls was more pronounced at one month, compared 
A
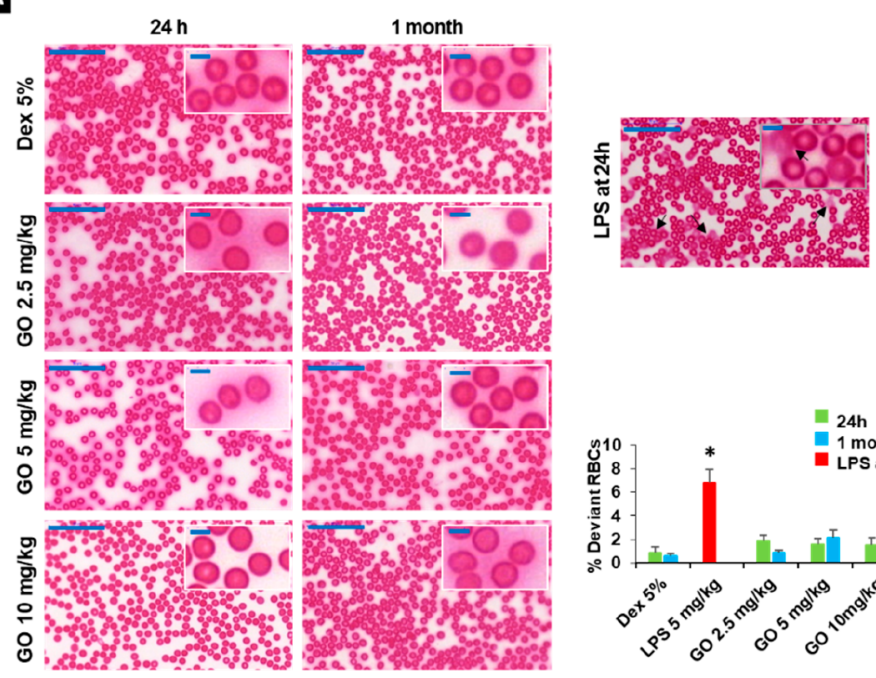

B
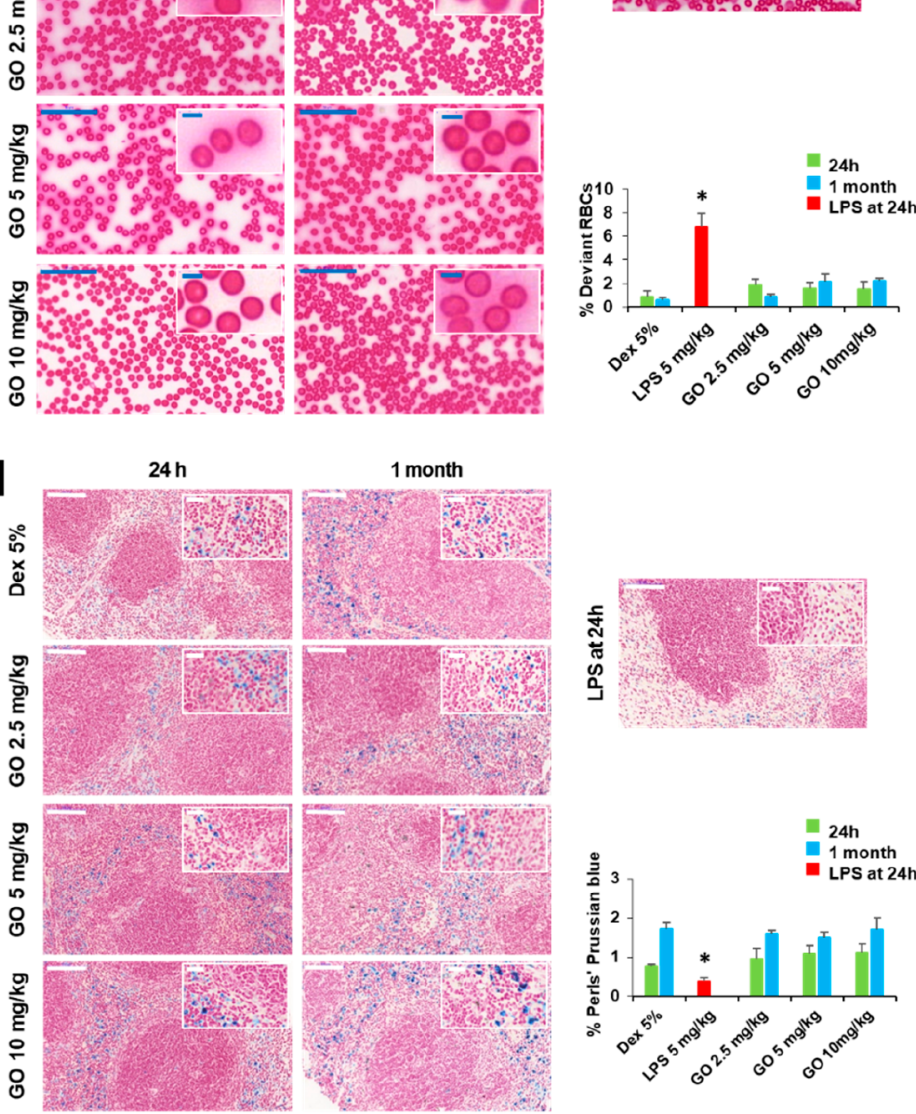

c
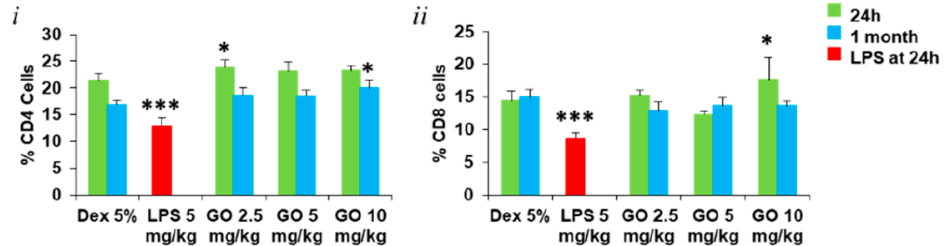

D

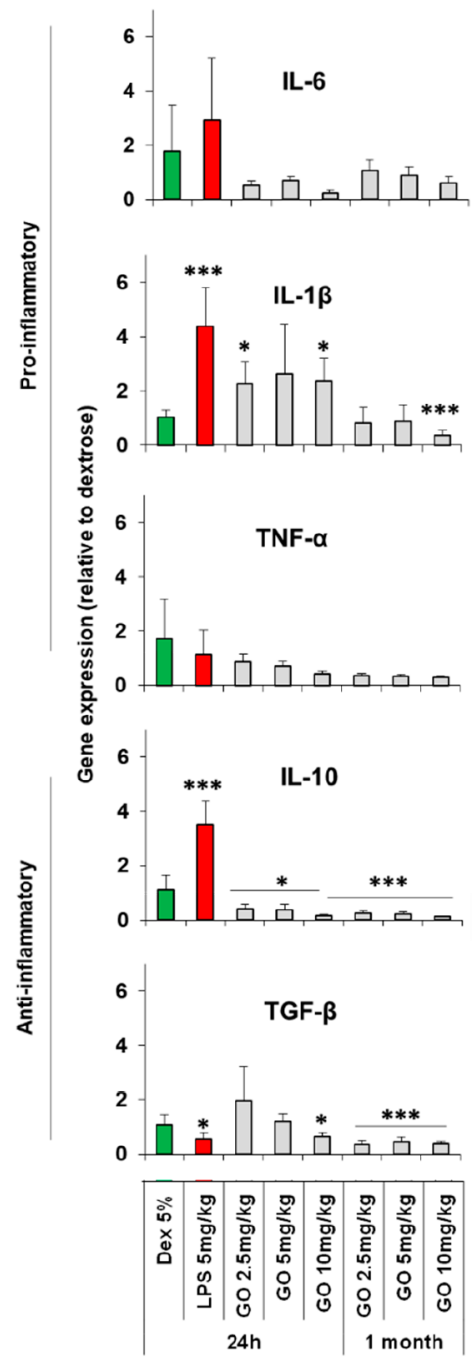

Figure 3. Effect of GO on spleen function, after $24 \mathrm{~h}$ and one month postinjection of $\mathrm{GO}$ at different concentrations $(2.5,5,10 \mathrm{mg} / \mathrm{mL})$ compared with control mice, Dex $5 \%$ (negative control), and LPS $5 \mathrm{mg} / \mathrm{kg}$-injected (positive control) mice. (a) Blood smears stained with $\mathrm{H} \&$ $\mathrm{E}$ at two magnifications, $60 \times($ scale bar $50 \mu \mathrm{m})$ and inset images $300 \times($ scale bar $5 \mu \mathrm{m})$. The graph represents the percentage of deviant RBCs (reticulocytes, abnormal and aged RBCs) from the total RBC counts; the black arrows indicate some of the deviant RBCs detected in LPSinjected mice. The graph was obtained after counting $>500$ cells from each mouse $(n=3$ per group). (b) Pearls' Persian blue-stained spleen tissue sections $(5 \mu \mathrm{m}$ thick) at two magnifications, $20 \times($ scale bar, $100 \mu \mathrm{m})$ and inset images $100 \times(\mathrm{scale}$ bar, $20 \mu \mathrm{m})$. Blue spots demonstrate regions of Persian blue-stained hemosiderin. The graph represents the percentage of total imaged tissue that stained blue, indicating the presence of hemosiderin. This was obtained by measuring the intensity of the blue-stained regions from 3 or 4 images from each mouse captured at $20 \times\left(n=3,4\right.$ mice per group) by Fuji Image J analysis. (c) Spleen T-lymphocyte cell counts, CD4 ${ }^{+}$T-helper cell counts plot (left), and cytotoxic $\mathrm{CD8}^{+}$cell count plot (right). Cell counting was performed by flow cytometry. Three repeat counts were performed for each group of mice $(n=3)$. (d) Gene expression levels of pro-inflammatory cytokines IL-6, IL-1 $\beta$, and TNF- $\alpha$ and gene expression levels of anti-inflammatory cytokines IL-10 and TGF- $\beta$. (a) and (b) represent the spleen hematological function, while (c) and (d) represent the spleen immunological functions. In (a), (b), and (c) data are represented as mean \pm standard error (SE), while for the RT-q-PCR in (d), data are represented as mean \pm standard deviation (SD). Statistical significance was performed by using the Kruskal-Wallis multiple comparison test and Dunn's posthoc test, while the Welch ANOVA and Games-Howell's posthoc test was used in D. In all cases statistics are $* p<0.05, * * p<0.01, * * * p<0.005 v s$ negative control. 
with $24 \mathrm{~h}$. At one month, the presence of brown-pigmented cells was also evident in the white pulp at the maximum dose $(10 \mathrm{mg} /$ $\mathrm{kg}$ ). In our previous study, a similar appearance of dark brown/ black pigmented cells was noted in the red pulp of spleens of mice injected with functionalized GO sheets $(f \mathrm{GO}) .{ }^{9}$ Other studies have also reported dark local regions in the $\mathrm{H} \& \mathrm{E}$ stained tissue sections of organs (including lungs and liver) following administration of $\mathrm{GO}$ or $f \mathrm{GO} .^{43-45}$ The dark local regions in these studies were attributed to accumulation of foreign carbon nanostructures. ${ }^{46}$ However, at this level of information, dark or brown regions could be indicative of substances other than GO, such as iron, which is known to be stored in the spleen as hemosiderin, preferentially in the red pulp. ${ }^{47,48}$ In addition to the microarchitecture, the general appearance of the whole spleen was examined (Figure S3). During the early stages, i.e., 24 $\mathrm{h}$ after injection, there was a notable darkening of the spleens particularly following the injection of the highest GO doses. Wen et al. demonstrated a similar dark black coloration of the whole spleen in mice injected with $f \mathrm{GO}$. This darkening also increased when the administrated dose (up to $16 \mathrm{mg} / \mathrm{kg}$ ) increased. ${ }^{49}$

To further assess the possible impact of GO i.v. injection at the tissue level, terminal deoxynucleotidyl transferase (TdT) dUTP nick-end labeling (TUNEL) staining was performed on spleen sections (Figures S4 and S5). While the LPS-positive control was clearly inducing a higher number of TUNEL-positive cells compared with the negative control, GO was consistently inducing a higher number of TUNEL-positive apoptotic cells (about twice the amount found in negative control) for both time points tested, only at the highest tested dose (i.e., $10 \mathrm{mg}$ / $\mathrm{kg}$ ). Although the total number of TUNEL-positive apoptotic cells in GO groups was still within the norms expected for the spleen, ${ }^{50,51}$ but significantly lower than in the LPS control, these findings were suggestive that $10 \mathrm{mg} / \mathrm{kg}$ could likely be the lowest-observed-adverse-effect level (LOAEL) for the tested material in this animal model.

\section{GO SHEETS HAVE LIMITED EFFECTS ON SPLENIC FUNCTION}

In order to further study the effect of GO on the spleen and clarify the possible risk associated with the $10 \mathrm{mg} / \mathrm{kg}$ dose, the two main splenic functions, namely, hematological and immunological, were interrogated. The hematological function concerns primarily the ability of the red pulp macrophages to eliminate aberrant and old RBCs. ${ }^{52-56}$ Figure $3 \mathrm{~A}$ presents optical microscopy images of $\mathrm{H} \&$ E-stained blood smears of mice injected with GO at doses of $2.5,5$, or $10 \mathrm{mg} / \mathrm{kg}$, at $24 \mathrm{~h}$ and one month compared with those of mice injected with Dex $5 \%$ (negative control) or $5 \mathrm{mg} / \mathrm{kg}$ LPS (positive control). Black arrows indicate deviant RBCs in a representative LPS-injected mouse blood smear. Quantification of the deviant RBCs is provided as bar chart in the same figure. Aberrant RBCs normally do not account for more than $3 \%$ of total RBCs. ${ }^{57}$ The graph, therefore, presents evidence of normal levels of aberrant RBCs (about 3\%) ${ }^{57}$ for all groups injected with GO, regardless of the concentrations, at both $24 \mathrm{~h}$ and one month after administration. The LPS-injected group (positive control), however, exhibited elevated levels of abnormal RBCs (7\%) relative to the negative control (Dex 5\%) and significantly above the physiological level (3\%). ${ }^{57}$ This was expected, as LPS administration has been shown to result in increased RBC deformation. $^{41}$
The other aspect of hematological function ${ }^{58}$ of the spleen is its capacity to serve as a reservoir for biologically important metals, such as iron in the form of hemosiderin in red pulp macrophages. $^{59-61}$ Figure $3 \mathrm{~B}$ presents Perls' Prussian blue staining that was used to detect the hemosiderin content (stained in blue; quantification presented in bar chart) in mouse spleen sections at $24 \mathrm{~h}$ and one month after injection with different concentrations of GO $(2.5,5$, or $10 \mathrm{mg} / \mathrm{kg})$. As expected, the levels of hemosiderin increased with the age of the mice (as seen in Dex 5\%-treated animals between the $24 \mathrm{~h}$ and 30 day time points). As also expected, there was a significant reduction in the amount of hemosiderin in LPS-treated mice; this can be attributed to the marked cell death known to be induced by LPS. ${ }^{62}$ At $24 \mathrm{~h}$ and one month, neither a decrease nor increase in hemosiderin was observed in GO-treated mice, regardless of dose, when compared with age-matched Dex 5\%treated mice.

Taken together, these results indicated that the spleen was able to maintain both a healthy RBC population (Figure $3 \mathrm{~A}$ ) and its iron-storage capability (Figure $3 \mathrm{~B}$ ) after GO administration irrespective of the dose used. Other studies have reported a similar absence of changes in the overall spleen hematological parameters of mice injected with a single dose of GBMs of up to $10 \mathrm{mg} / \mathrm{kg}$ after $48 \mathrm{~h}^{43}$ and 10 days, $^{63}$ or even with doses as high as $60 \mathrm{mg} / \mathrm{kg}$ after $24 \mathrm{~h} .{ }^{64}$ The same finding is true after repeated administration of $10 \mathrm{mg} / \mathrm{kg}$ every 2 days for up to 22 days, ${ }^{65} 15$ $\mathrm{mg} / \mathrm{kg}$ every other day for 14 days, ${ }^{66}$ or even after repeated oral administration of high doses of GO $(60 \mathrm{mg} / \mathrm{kg})$ every $24 \mathrm{~h}$ for five consecutive days. ${ }^{67}$

In addition to providing information about the hematological function of the spleen, the Perls' Prussian blue staining provided additional information concerning the identity of the brownpigmented features, previously observed in the splenic marginal zones of GO-treated mice (Figure 2). Most of the brown material in the red pulp was stained blue and, therefore, was confirmed to be hemosiderin. In contrast, in cells of the splenic marginal zone, or their close vicinity, brown material (unstained by the Perls' Prussian blue dye) continued to be observed in spleen sections of GO-treated mice, compared with control groups. This further confirmed that the brown-pigmented material present in the marginal zones of GO-treated mice was not hemosiderin but more likely GO.

We then investigated the immunological function of the spleen (Figure 3C and D). Emphasis was put on cell-mediated immunity, which was measured by determining the populations of $\mathrm{T}$ lymphocytes, specifically $\mathrm{CD} 4^{+}$and $\mathrm{CD} 8^{+}$cells as the major immune component of the splenic white pulp. ${ }^{68,69}$ Cellmediated immunity has a crucial role in the recognition and elimination of antigenic substances such as abnormal cells and foreign matter. ${ }^{15}$ Cell counts for both $\mathrm{T}$ helper $\mathrm{CD} 4^{+}$and $\mathrm{T}$ cytotoxic $\mathrm{CD}^{+}$cells are presented in Figure 3C (representative flow cytometry plots outlining $\mathrm{CD} 4^{+}$and $\mathrm{CD} 8^{+}$populations are provided in Figure S6). The graph shows that there were moderate changes in $\mathrm{CD}^{+}$and $\mathrm{CD} 8^{+}$cell populations in mice injected with GO $(2.5,5$, and $10 \mathrm{mg} / \mathrm{kg})$ at both $24 \mathrm{~h}$ and one month after administration when compared with the agematched negative controls (Dex 5\%). In contrast, LPS-injected mice showed a significant reduction in both cell populations (Figure 3C). These data were in agreement with the findings of Wang et al., who showed no changes in $\mathrm{CD}^{+}$and $\mathrm{CD}^{+} \mathrm{T}$-cell populations in spleens of mice injected with two different types of graphene nanosheets at $1 \mathrm{mg} / \mathrm{kg}$ after i.v. injection. ${ }^{45}$ Interestingly, the same study demonstrated that there was a 

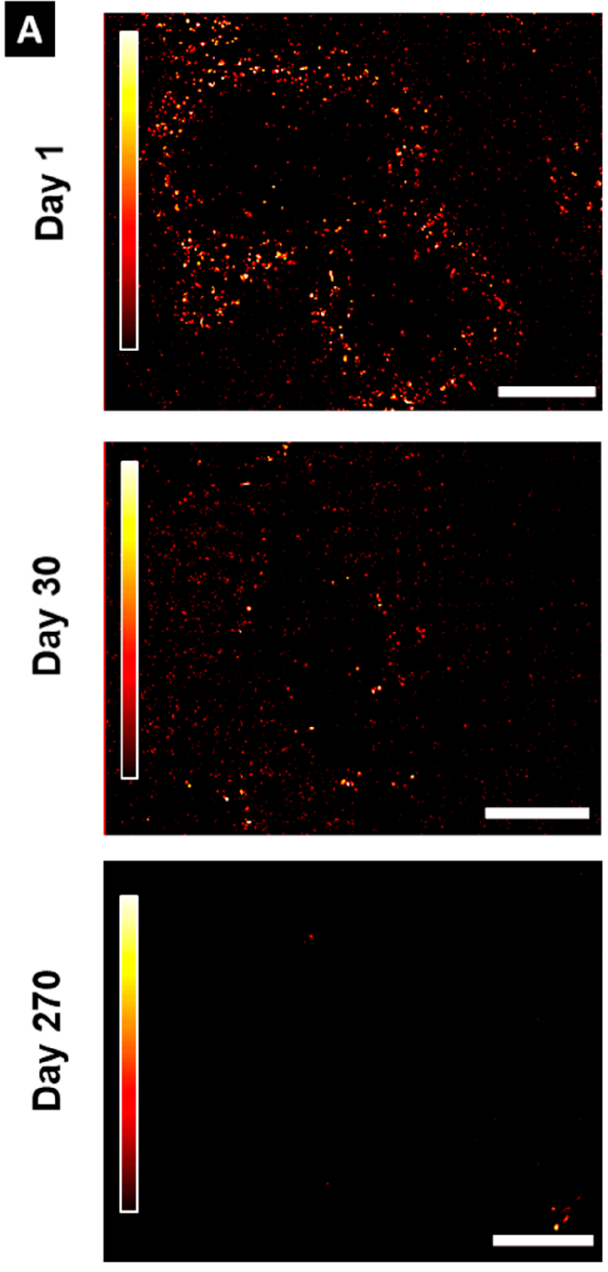

C

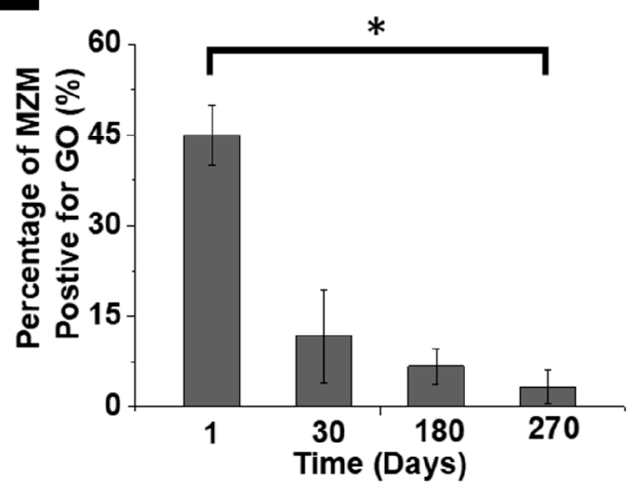

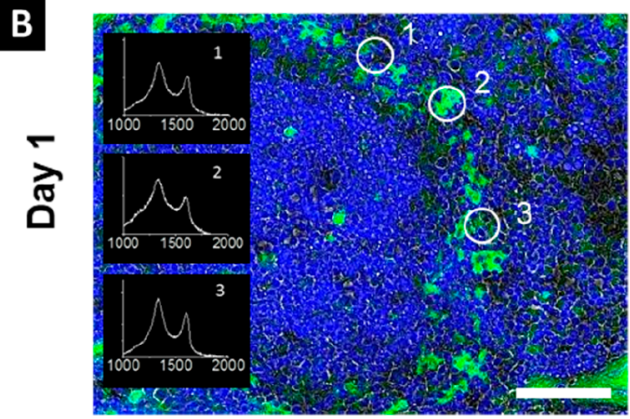
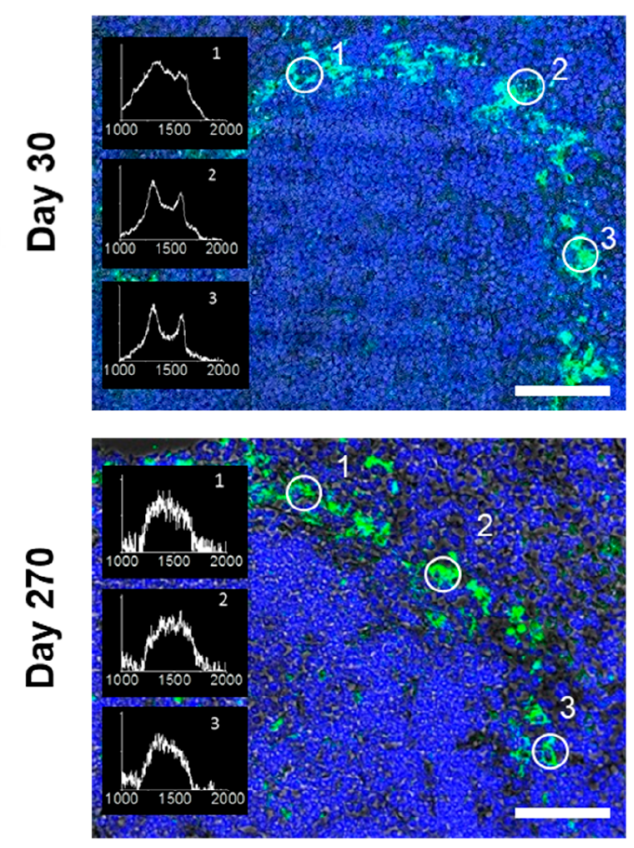

D

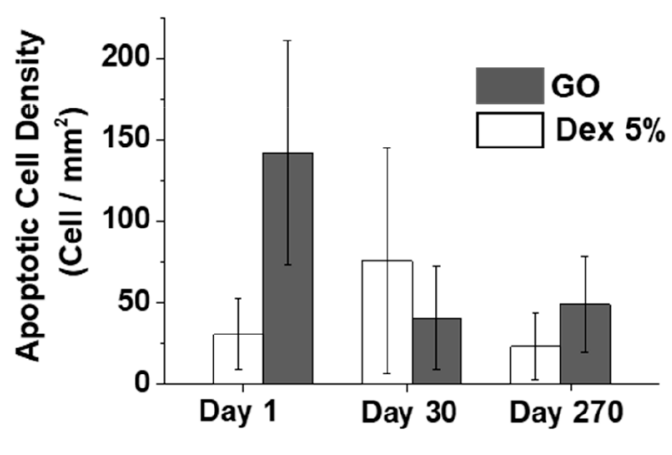

Figure 4. Localization and abundance of GO in spleen tissue at different time points following the administration of $7.5 \mathrm{mg} / \mathrm{kg} \mathrm{GO}$. (a) Confocal Raman correlation maps of GO Raman signatures detected in mice spleen sections at different time points (day 1, 30, and 270) post-GO administration. The horizontal length scale bar represents $200 \mu \mathrm{m}$. The vertical heat scale bar (black-white) indicates $40-80 \%$ correlation with spectra of starting material shown in Figure 1c. (b) Overlay image of the immunostaining of MZM (green) and nuclei (blue) with bright field images, together with correlative Raman spectra of regions of interest, at different time points (day 1, 30, and 270). The white circles and their corresponding numerical identities indicate different regions of interest where the Raman spectra were acquired. The corresponding numbered spectra are inset in the respective images. Scale bars represent $50 \mu \mathrm{m}$. (c) The percentage of cell-sorted MZMs that screened Raman positive for GO over time ( $n=20$ spectra for each of three animals at each time point). (d) Apoptotic cell density detected as per the TUNEL assay, for GO and Dex $5 \%$ treated groups at different time points (day 1, 30, and 270). Statistical significances were tested using the Kruskal-Wallis multiple comparison test with Dunn's posthoc test. A full breakdown of the results of the statistical analysis for graphs $\mathrm{C}$ and $\mathrm{D}$ is provided in Tables $\mathrm{S} 1$ and S2, respectively. In all cases, statistical significance was defined where $p<0.05$.

significant rise in both $\mathrm{CD}^{+}$and $\mathrm{CD}^{+} \mathrm{T}$ cells after administration of multiwalled carbon nanotubes (CNTs) at the same dose and that this rise persisted for more than 7 days. ${ }^{45}$
Such results illustrate how different types of carbon nanoma-

terials (GBMs or CNTs) may interact with biological systems in 
different ways and, thereby, result in different biological outcomes. $^{5}$

To expand our study on the immunological function of the spleen, we analyzed the gene expression profiles of various cytokines, including pro-inflammatory (IL-6, IL- $1 \beta$, and TNF$\alpha$ ) and anti-inflammatory (IL-10 and TGF- $\beta$ ) mediators. Rise in cytokine expression is typical evidence of $\mathrm{CD}^{+} \mathrm{T}$-cell activation and is known to mediate $\mathrm{CD}^{+}$cells' and B-cells' functions. ${ }^{14}$ Herein, no significant differences in the levels of the proinflammatory cytokines IL- 6 and TNF- $\alpha$ were detected at any time point in mice injected with GO $(2.5,5$, or $10 \mathrm{mg} / \mathrm{kg}$ ) compared with mice injected with Dex 5\% (Figure 3D). This was in agreement with the findings of Wang et al., who also did not detect any change in cytokine levels following the i.v. injection of graphene nanosheets, even 1 week after administration. ${ }^{45}$ There was, however, a significant increase at $24 \mathrm{~h}$ in IL-1 $\beta$ expression for all GO-injected mice (Figure 3D); this increase was also noted by Orecchioni et al. at $24 \mathrm{~h}$ after the incubation of GO with human immune cells. ${ }^{70}$ After one month, IL- $1 \beta$ levels returned to normal in mice treated with the lowest concentrations of GO $(2.5$ and $5 \mathrm{mg} / \mathrm{kg})$, indicating that this effect was transient and due to a mild inflammatory response occurring soon after injection. However, at $10 \mathrm{mg} / \mathrm{kg}$ and in contrast to the 2.5 and $5 \mathrm{mg} / \mathrm{kg}$ doses, IL- $1 \beta$ levels were significantly reduced at the one-month time point. Noticeably, there was also a significant reduction in anti-inflammatory cytokine expression at $24 \mathrm{~h}$, in particular IL-10 in mice injected with $2.5,5$, and $10 \mathrm{mg} / \mathrm{kg}$ of GO, and TGF- $\beta$ in mice injected with $10 \mathrm{mg} / \mathrm{kg}$ of GO. Levels of both IL- 10 and TGF- $\beta$ were also significantly reduced at the one-month time point for all tested GO doses.

Such cytokine suppressive effects of GO have been previously reported by Sydlic et al. following the administration of GO at 20 $\mathrm{mg} / \mathrm{kg} .{ }^{71}$ The authors attributed such effects to a protective mechanism associated with the adverse effects of GO. ${ }^{71}$ Suppression of cytokine expression could also be due to direct inhibitory effects of GO on secreting cells (e.g., primarily macrophages in the case of TGF- $\beta^{72}$ or monocytes and macrophages in case of both IL- $10^{73}$ and IL- $1 \beta^{74}$ ) by a mechanism that does not involve secondary regulatory effects ${ }^{75}$ or decreased responsiveness of such cells. ${ }^{76} \mathrm{~T}$ cells are the main source of IL- $6,{ }^{77}$ while TNF- $\alpha$ is primarily secreted by macrophages but can also be produced by other cells, such as $\mathrm{CD}^{+} \mathrm{T}$ cells. $\mathrm{T}$-cell populations were, however, unaltered in the present study (Figure 3C); reduction in cytokine expression after GO treatment may, therefore, indicate the involvement of the innate immune system in regulating the effects of GO. ${ }^{70}$ More in-depth work is warranted to assess this possibility.

\section{GO SHEETS ACCUMULATE PREFERENTIALLY IN MARGINAL ZONE MACROPHAGES AFTER I.V. ADMINISTRATION, BUT PROGRESSIVELY DISAPPEAR FROM THE SPLEEN OVER NINE MONTHS}

Following the determination of the impact of GO on mouse spleen, we analyzed the sub-splenic biodistribution of the material to reveal its long-term fate within this organ. For this experiment, we used $7.5 \mathrm{mg} / \mathrm{kg}$ of GO, rather than the maximum $10 \mathrm{mg} / \mathrm{kg}$ dose used in the above experiments. This selection was based on observations that $10 \mathrm{mg} / \mathrm{kg}$ could induce moderate but potentially significant modifications of the immunological function of the spleen (Figure 3D); increase cell apoptosis, despite being within a physiological range for mouse spleen $^{50,51}$ (Figure S5); and our previous observations ${ }^{27}$ of uncharacteristic mouse growth curves at this dose after one month. All observations suggested that $10 \mathrm{mg} / \mathrm{kg}$ might be the LOAEL dose in mice for this material over the long term. Therefore, we selected a lower dose (i.e., $7.5 \mathrm{mg} / \mathrm{kg}$ ) to reduce the long-term risk to the animals' health. This was important, as we intended to study biodegradation over nine months, while not compromising our ability to detect and track the fate of GO during this long period. In agreement with this approach, no impact on the growth curve of the GO-injected mice was observed compared with the vehicle (Dex 5\%) control-injected mice (Figure S7) over the nine-month period.

Using confocal Raman mapping to track the injected GO sheets in spleen sections, it was confirmed without ambiguity that the observed brown material in the splenic marginal zone had typical Raman spectroscopic fingerprints of GO (Figure 4A, day 1). Previous literature studies have reported similar accumulation in this region for other engineered nanoparticles, including lipid-based nanoparticles ${ }^{10,78}$ and $\mathrm{CNT}^{40,79}$ In the spleen, the marginal zone is densely populated with various strategically located phagocytic cells. ${ }^{10}$ The next step was, therefore, to determine the precise identity of the specific cells within the splenic marginal zone that sequestered GO. Using immunofluorescence in correlation with conventional (pointand-shoot) Raman spectroscopy in spleen sections, we found that GO was sequestered primarily within a subset of splenic macrophages. These were shown to be the marginal zone macrophages (MZM), which stained positive for the ERTR-9 antigen, ${ }^{10}$ and were shown to contain GO by Raman analysis (Figure 4B). Preferential uptake of GO by MZMs was further confirmed using fluorescence-activated cell sorting (FACS) followed by conventional Raman spectroscopy on isolated splenocyte subpopulations (Figure 4C and Figure S8).

Within the spleen, MZMs make up a small fraction of the total splenocytes and are situated throughout the middle and outer portion of the marginal zone. ${ }^{80}$ In these regions of the spleen, blood, previously flowing under high pressure due to the restrictive diameter of the terminal arterioles, emerges from the white pulp and into the sinuses of the marginal zone. ${ }^{13}$ Due to the open nature of this region, there is a lack of resistance, which causes the blood to experience a dramatic deceleration in flow velocity, resulting in a local decrease in blood pressure. ${ }^{10,13}$ Highly phagocytic MZMs take this opportunity to remove unwanted particulates, including cellular debris and exogenous particulates from the blood. ${ }^{10,13} \mathrm{We}$ infer that GO sheets circulating in the blood may have in the same way been taken up by the MZMs, which have been repeatedly shown to internalize engineered nanoparticles, including liposomes, ${ }^{10,11}$ polystyrene microspheres, ${ }^{10}$ or CNTs, ${ }^{40}$ after i.v. administration.

We then attempted to probe the fate of the GO accumulated in the marginal zone over time (from day 1 to day 270 after administration, Figure 4A and B). Comparing spleen sections from GO-injected mice analyzed at the different time points, we observed a clear decrease in the abundance of detectable GO and a corresponding loss in the GO Raman spectral integrity from day 1 to day 270. Results from confocal Raman mapping of spleen sections (Figure 4A) agreed with that of conventional (point and shoot) Raman spectroscopy on individual splenocytes (Figure 4B). In both cases, while the Raman signature of GO was easy to identify at $24 \mathrm{~h}$, the same signature could hardly be detected at the later time points. The greatest loss in GO-positive cells was observed during the first month after administration (between day 1 and day 30), but it 
A

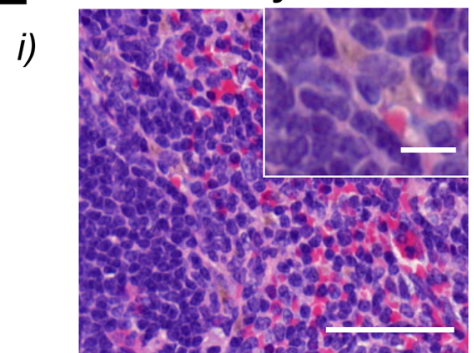

ii)

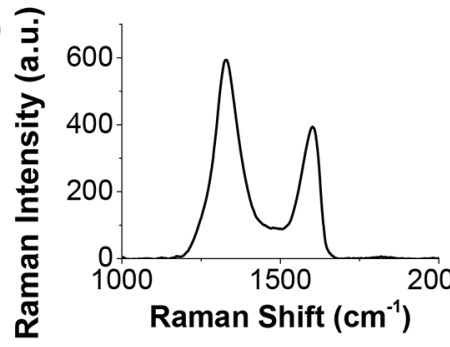

Day 30

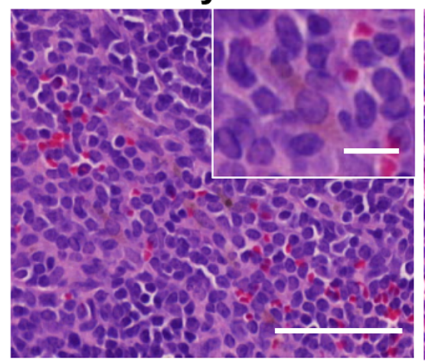

Day 270
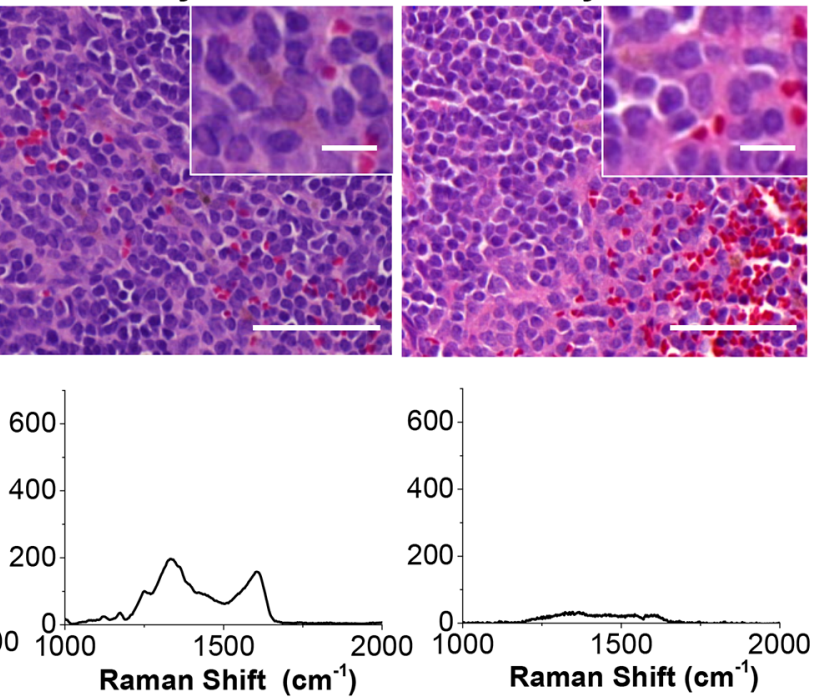

iii)
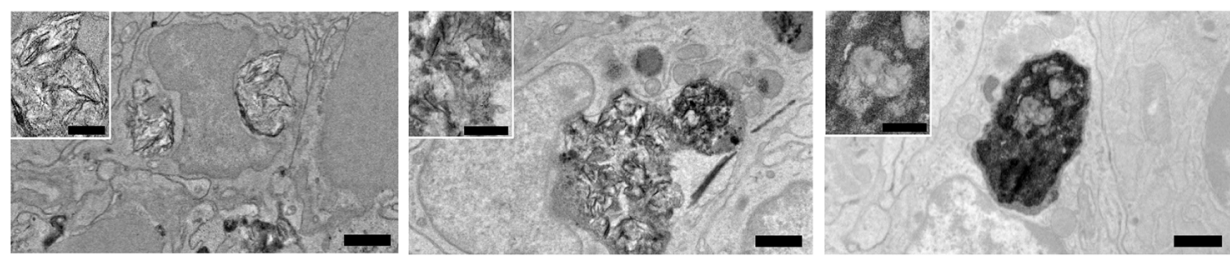

iv)
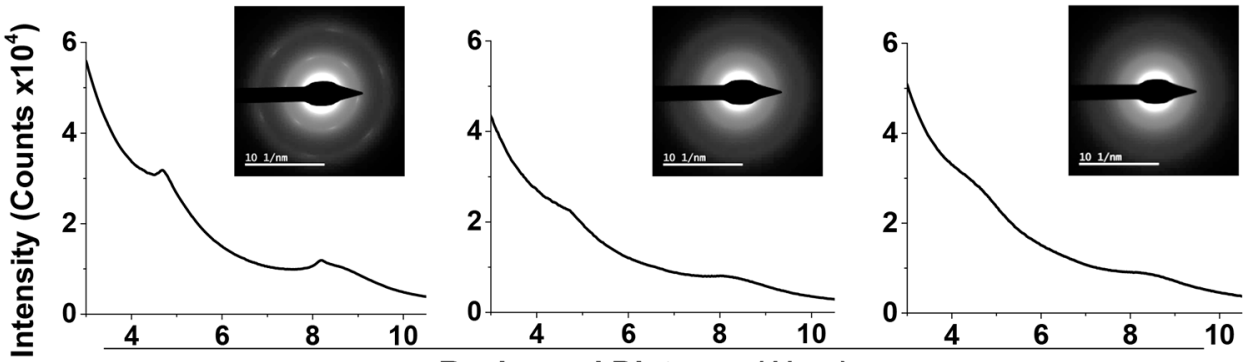

Reciprocal Distance $(1 / \mathrm{nm})$

B

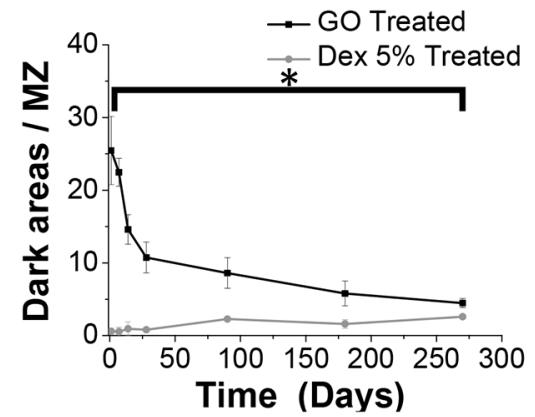

C

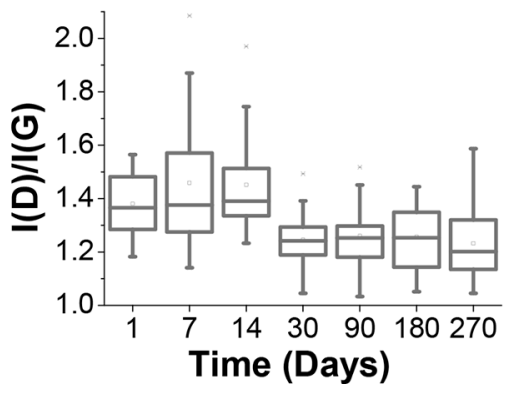

Figure 5. Splenic biodegradation of GO over nine months following i.v. administration at a dose of $7.5 \mathrm{mg} / \mathrm{kg}$. (a) (i) Splenic sections of mice that were stained with $\mathrm{H} \& \mathrm{E}$; scale bars represent $50 \mu \mathrm{m}$. Inset images show the presence of GO material in the vicinity of cells of the marginal zone; scale bars represent $10 \mu \mathrm{m}$. (ii) Average Raman spectra of GO present in physically homogenized spleen tissue at different time points, $n=$ 10 ROI $\times 3$ mice. (iii) TEM micrographs of GO sequestered within the vesicular compartments of marginal zone splenocytes over time; scale bars represent $1 \mu \mathrm{m}$. The inset shows a magnification of the GO material at the respective time points; scale bars represent $500 \mathrm{~nm}$. (iv) Representative electron diffraction pattern line profiles of GO at different time points postadministration, with the respective diffractograms inset; scale bars represent $101 / \mathrm{nm}$. (b) Average number of dark areas present in the splenic marginal zone at each time point $(n=5 \mathrm{ROI} \times 3$ mice) $(* p<0.05)$. (c) Evolution of the Raman $I(D) / I(G)$ ratio over nine months $(n=10$ ROI $\times 3$ mice $)$. Statistical significances for graphs B and $\mathrm{C}$ are given in Tables S3 and S4, respectively.

continued to decrease over the remaining course of the experiment (Figure 4C).

Observation of loss of GO Raman signature may on one hand be due to biodegradation of the material, leaving only a trace amount of GO crystalline regions that were below the limit of detection of Raman spectroscopy. ${ }^{81}$ On the other hand, it could be explained by the elimination of the material. Indeed, it has been previously shown that nanomaterials traveling through blood can be noncovalently attached to RBCs. ${ }^{82}$ If this was the case for $\mathrm{GO}$, the sheets would be held in the $\mathrm{RBC}$ reservoir of the 
spleen and would exit the organ carried by healthy RBCs without being captured by phagocytic cells. However, this hypothesis would not fit with the biodistribution pattern observed herein, since the majority of RBCs within the spleen are present in the red pulp ${ }^{13}$ and not in the marginal zone where GO appeared to accumulate (Figure 3D). Our previous studies ${ }^{9,27}$ have also shown that a large portion of administrated GO sheets are excreted via the urinary tract (without causing damage to the kidneys) soon after i.v. administration; this would not be possible if large amounts of GO were bound to RBCs. This suggests that GO sheets are more likely relatively free and not carried by RBCs when circulating in the blood, leading to their capture by MZMs when reaching the spleen.

Another possibility that would explain an over-time elimination would be GO sheets inducing significant tissue damage upon accumulation, which in turn would cause release of splenic content, including iron (hemosiderin) ${ }^{83}$ and the captured GO. However, our results showed no detectable damage to the spleen (or decrease of hemosiderin) for up to one month (Figures 2 and 3), when the greatest loss of GO signal was observed. Similarly, no significant differences in the number of apoptotic cells were found in the spleen of GO-injected mice even after nine months (Figure 4D), although there was an initial slight but statistically insignificant increase at day 1 . However, the extent of cell death was within the norm expected for spleen tissue..$^{50,51}$ In addition, on examining the TUNELstaining images, it is apparent that apoptosis was not predominant in the marginal zone (Figure S9), where the densest accumulation of GO was observed, at any time point.

Without completely negating the possibility of concomitant elimination of the material via mechanisms that would require further investigation, the absence of compelling evidence to support elimination of the material leads us to conclude that biodegradative processes were the more likely leading cause for the loss of GO Raman signature in spleen sections. This conclusion is supported by several studies showing that thin and well-dispersed GO sheets, similar to those used in the present study, are more likely to undergo biodegradation compared with thicker and aggregated GO sheets in the presence of oxidative enzymes. ${ }^{17,18}$ In particular, myeloperoxidase, an enzyme typically produced by granulocytes and macrophages, including MZMs, was shown to be unable to degrade highly aggregated GO, but efficiently catalyzed degradation of well-dispersed GO materials, ${ }^{17}$ such as those used herein. Such studies emphasize the key role of the hydrophilicity, negative surface charge, and colloidal stability of aqueously dispersed GO in relation to biodegradation. In addition to this, the spleen has been previously shown to have a stronger capacity to biodegrade GBMs (especially GO-like, carboxylated graphene) ${ }^{6}$ than other components of the MPS such as the lungs and liver. ${ }^{6,42}$

\section{GO SHEETS BIODEGRADE IN THE MARGINAL ZONE MACROPHAGES OVER NINE MONTHS}

To further characterize the progressive in vivo biodegradation of GO over nine months, we looked in more detail at the spleen marginal zone cells in which GO sheets accumulate preferentially. First, using $\mathrm{H}$ \& $\mathrm{E}$ staining, we found evidence of the consistent presence of slightly darkened regions within the marginal zones of the spleen, at all tested time points (Figure 5Ai). This agreed with the data presented in Figures 2-4, in which dark regions were observed across the whole spleen. However, these dark regions were present not only in GO-injected mice (Figure 5A-i) but also in the Dex 5\%-administered mice, albeit more sparingly (Figure S10). The number of dark regions was, therefore, quantified (Figure 5B) and revealed a clear association between the higher number of dark regions in the marginal zone and GO administration, compared with vehicle controls. Importantly and consistent with the idea of progressive degradation of $\mathrm{GO}$, the number of marginal zone dark regions in GO-treated mice decreased over time (more sharply during the first 30 days), reaching values similar to those found in Dex $5 \%$-treated mice by day 270 (Figure 5B).

To further confirm that progressive degradation of GO entrapped in the spleen was taking place in GO-injected animals, conventional Raman spectroscopy was used to detect the typical Raman fingerprints of GO in physically homogenized spleen tissue of mice injected with GO at different time points and for up to nine month after administration. This allowed us to probe GO biodegradation at the whole organ level, to reveal the full extent of degradation for all the GO sheets entrapped in the spleen. In agreement with previous data (Figure 4), we found that the intensity of the Raman signature of GO dramatically decreased over time (Figure 5A-ii). By nine months, the GO Raman signature was barely recognizable, lacking all typical spectral features of GO crystals. For reference, the complete series of averaged spectra $(n=30)$ over the nine month study is provided in Figure S11.

Going further in the analysis of the collected Raman spectra, we extracted the peak intensity for the characteristic D vs $\mathrm{G}$ bands of GBMs (D band at $\sim 1350 \mathrm{~cm}^{-1}$; G band at $\sim 1580$ $\mathrm{cm}^{-1}$ ) and calculated the $I(\mathrm{D}) / I(\mathrm{G})$ intensity ratio for each time point (Figure $5 \mathrm{C}$ ). The data revealed that over nine months the GO Raman signature in the spleen followed the expected threestage classification of disorder for graphitic carbon crystals. ${ }^{84}$ This theory is known as the amorphous trajectory of carbon and describes the transformation of $\mathrm{sp}^{2}$-hybridized carbon structures into a mainly tetrahedral $\mathrm{sp}^{3}$ amorphous carbon phase. ${ }^{84}$ Prior to injection, the GO material displayed a prominent $\mathrm{D}$ peak (Figure 1), which is due to the breathing modes of $\mathrm{sp}^{2}$ hybridized carbon bonds present in the structure's hexagonal rings. In order for the $\mathrm{D}$ peak to be visualized, charge carriers must be inelastically scattered by a phonon and then undergo a second elastic scattering by a defect within the material. ${ }^{85}$ The presence of such a heightened D peak indicated, therefore, that prior to injection the GO sheets were significantly defective from a crystal point of view. This is expected considering the conditions of the modified Hummers' method used to oxidize and exfoliate graphite to form GO. ${ }^{28,34,86}$ From day 1 to day 7 after administration, the $I(\mathrm{D}) / I(\mathrm{G})$ ratio of $\mathrm{GO}$ in the spleen began to rise (Figure $5 \mathrm{C}$ ), indicating that the degree of defects within the material had increased, as expected per the first stage of the amorphous trajectory of carbon and in correlation with predictions of the Tuinstra-Koenin (TK) equation. ${ }^{87}$ The TK equation relates the size of $\mathrm{sp}^{2}$-hybridized crystal domains within graphitic materials as they become increasingly defective. The equation predicts that as the size of the $\mathrm{sp}^{2}$-hybridized crystal domain decreases, the $I(D) / I(G)$ ratio will increase until a minimum crystal domain size is reached. After this point, the $I(D) / I(G)$ is expected to decrease as the spectral peaks are gradually attenuated and the spectra are such that the assumptions of the TK equation no longer apply. ${ }^{84}$

The rise in the $I(\mathrm{D}) / I(\mathrm{G})$ ratio continued at a slow pace for another week after injection (from day 7 to 14; Figure 5C). This slow pattern can be explained by the presence of oxidized debris, physisorbed to the surface of GO sheets. Such debris may have degraded first, thereby offering protection to the underlying $\mathrm{GO}$ 
sheet, hence slowing the initial biodegradative process. The presence of oxidized debris may be alluded to by the XPS O/C atomic ratio $(\mathrm{O} / \mathrm{C}=0.5)$ measured in the $\mathrm{GO}$ material, prior to injection in animals. A previous study ${ }^{88}$ showed that GO, prepared through a modified Hummers' method, often contains significant quantities of physisorbed oxidized debris. These debris consist mainly of highly oxidized nanometer-sized polyaromatic molecules; their presence on GO sheets can lead to high $\mathrm{O} / \mathrm{C}$ ratios of around 0.4 or above. When such GO materials are subjected to base washing, shown to remove these physisorbed oxidized debris, significant reductions in the XPSderived $\mathrm{O} / \mathrm{C}$ ratio to values of approximately 0.3 or below are observed. ${ }^{88}$ This is due to the lower abundance of oxygen in the sample following the removal of the oxidized debris by the base washing. The protective effect of these oxidized debris may also be enhanced by the in vivo-derived protein corona, which is expected to form around any nanomaterial on contact with biological fluids such as blood.

After day 14, the $I(\mathrm{D}) / I(\mathrm{G})$ ratio was observed to decrease (in particular between day 14 and 30; Figure 5C), as expected as part of the second stage of the amorphous trajectory of carbon. It can be explained by the increasing presence of defects within the 2D structure of GO sheets, which eventually results in the presence of significant amounts of amorphous carbon structures, to such an extent that the assumptions of the TK equation no longer apply. ${ }^{84,89}$ This inference is supported by studies in which ion beams of increasing energies were directed at graphene sheets. In these cases, the ions caused knock-on damage, resulting in defects within the graphene sheets and consequent alterations in the Raman spectral features over time, ${ }^{85}$ which followed a similar pattern to what we observed herein for the spleen-bound GO. The results of these ion-beam studies were also discussed relative to the amorphous trajectory of carbon and predictions of the TK equation. ${ }^{85}$ Several enzyme- and cellbased studies investigating the biodegradation of GBMs also displayed a similar pattern of Raman $I(D) / I(G)$ ratio changes, albeit under much shorter time frames. ${ }^{18,90}$

The presence of an increasing amount of defects and disorder within the spleen-bound GO may also explain the increasingly difficult-to-detect GO Raman signals beyond $24 \mathrm{~h}$ (as observed in both conventional Raman spectroscopy $\left(1 \mu \mathrm{m}^{2}\right.$ spot size; Figure 4B, Figure 5A-ii) and confocal Raman mapping $\left(\mathrm{mm}^{2}\right.$ wide tissue section area; Figure 4A)). Indeed, as time progressed, attenuation of the two characteristic Raman scattering peaks continued to occur, with subsequent decreases in the $I(\mathrm{D}) / I(\mathrm{G})$ ratio (Figure 5C) until both peaks were hardly detectable. By day 270, attenuation of both $\mathrm{D}$ and $\mathrm{G}$ bands was consistent across samples with limited exceptions, indicating that the crystalline structure of the accumulated material had been largely lost (Figure 5A-ii).

We finally wanted to confirm visually that biodegradation of GO was occurring within the splenocytes and not extracellularly. BF-TEM was used to image GO directly within the ultrastructure of tissue-fixed cells. An acceleration voltage of $80 \mathrm{kV}$ was used, in order to reduce knock-on damage. ${ }^{91}$ Cell-entrapped GO appeared to lose its characteristic appearance and become increasingly defective over time (Figures 5A-iii and S12). This was further validated by the evolution of the electron diffraction patterns of intracellularly entrapped GO, which became increasingly difficult to acquire (Figures 5A-iv and S13). At day 1 , it was relatively easy to locate intracellular GO structures and acquire hexagonal diffraction patterns characteristic of GO within cellular compartments (Figure 5A-iii and A-iv). However, at longer time points, there was an overall decrease in the abundance of material as well as the intensity measured for the diffraction peaks associated with GO. This was attributed to a progressive attenuation of the crystallinity of the GO to a more amorphous structure due to biodegradation, ${ }^{17}$ as discussed above and supported by the Raman results (Figures 5C and S11). In further support of these findings, evidence of the formation of holes within the planar structure of GO sheets was identified at day 30 (Figure S14). These formations were not apparent prior to injection or at early time points, i.e., before day 30 , and could not be attributed to electron beam damage during image acquisition. Beyond 30 days, cell-entrapped GO sheets appeared too damaged to allow TEM imaging of further degradation (i.e., more advanced holey formation) of the planar structure. These observations and their time line may suggest a structural biodegradation-related GO transition state, whereby defects accumulate within the material and then erode away, resulting initially in the creation of large holes within the GO sheets and ultimately the complete loss of their planar structure. Importantly, the structural changes in GO planes observed in spleen sections could not be found in GO sheets incubated at 37 ${ }^{\circ} \mathrm{C}$ in the dark for nine months (i.e., material not injected in animals; Figures S15 and S16), indicating that elements of the spleen biological milieu are likely responsible for these structural changes.

Similar results have been documented several times in vitro when $\mathrm{sp}^{2}$-hybridized carbon nanomaterials, including GBMs, were exposed to oxidizing chemicals, ${ }^{19}$ peroxidase family enzymes, ${ }^{17,18,23}$ and other enzymes such as cellular nicotinamide adenine dinucleotide phosphate-oxidase (NADPH oxidase) or induced nitrogen oxide synthase (iNOS). ${ }^{92}$ In terms of a possible mechanism by which the GO sheets were being biodegraded intracellularly, based on the extensive work concerning CNT degradation in macrophages, ${ }^{93}$ it can be envisioned that following phagocytosis in MZMs membranebound NADPH oxidase was activated and catalyzed the production of superoxide. Superoxide dismutase could then convert the superoxide into hydrogen peroxide, which could react with free radical nitric oxide to generate reactive peroxynitrite. Peroxidase enzymes such as myeloperoxidase (MPO) may also have a role in catalyzing production of hypochlorite from peroxide and chloride ions, even though macrophages, including MZMs, contain lower levels of MPO than other immune cells such as neutrophils. ${ }^{94}$ Another possibility is that $\mathrm{Fe}$ ions, present within macrophages, ${ }^{94}$ catalyzed the breakdown of peroxide to hydroxyl radicals. As a result of these different processes, free radicals and reactive species, including peroxynitrite, hypochlorite, and hydroxyl radicals, could then attack reactive sites such as epoxide groups present on the planes of GO sheets, resulting in hole formation (as observed herein via TEM) and the eventual breakdown of the whole graphitic lattice. Further research is, however, warranted to confirm which molecular mechanism(s) is(are) leading to biodegradation of GO in the mouse spleen.

An interesting and related question is the nature of the resulting molecular byproducts of biodegradation and whether they could be eliminated or not. Although we have not determined the molecular identity or fate of these in vivo generated degradation products, our study reveals that their likely production and presence did not obviously jeopardize the splenic health or growth curve of mice. Similarly, and in support of our findings, previous studies have reported that the in vivo administration of carbon nanomaterial biodegradation by- 
products, generated in vitro, lack toxic consequences for animal subjects. ${ }^{95,96}$ However, further studies would help determine the exact cellular mechanisms that catalyze the observed biodegradation of GO, as well as the precise molecular identity and fate of the resulting degradation byproducts, for the latter, using $\mathrm{GO}$ synthesized from ${ }^{13} \mathrm{C}$-labeled graphite for instance.

Besides the Raman, TEM, and electron diffraction properties of GBMs probed herein, the materials' photothermal properties could also be exploited in future studies to similarly reveal biodegradation; this would particularly be relevant to reduced GO. ${ }^{97,98}$ Such a concept was previously applied to functionalized CNTs in 2D microglial cell cultures. ${ }^{99}$ In this study, photothermal imaging was used to track the fate of CNTs over time, revealing their progressive disappearance from the phagocytic cells. The same technique could, therefore, be applied to quantitatively determine the dynamics of biodegradation of GBMs in biological systems.

In order to obtain more quantitative results regarding biodegradation, as most of the techniques used herein were at best only providing semiquantitative assessment, the use of simpler biological models, such as in vitro $3 \mathrm{D}$ cell culture models, should be explored. In these models, the applied/administrated dose, the delivered dose, and the cellular dose of nanomaterials may be easier to determine. Indeed, 3D cell culture models represent a convenient midway point between $2 \mathrm{D}$ cell culture models (which does not replicate adequately cell-cell and cellmatrix interactions or the complex diffusion/transport processes seen in $3 \mathrm{D}$ tissues $)^{100,101}$ and true in vivo animal models. Previous reports have demonstrated significant differences in the interaction of nanomaterials with $2 \mathrm{D}$ cell cultures compared with $3 \mathrm{D}$ cell cultures. ${ }^{100}$ This highlights the benefit of the latter as a more predictive and representative biological model, particularly when quantitatively determining critical doses of administered materials, and the dynamics of material degradation in cells, as recently reported for biosynthesized magnetic iron nanoparticles. ${ }^{102}$

\section{CONCLUSIONS}

We have provided evidence that following i.v. administration the small proportion of GO sheets that were not initially excreted but accumulated in the spleen did not induce histopathologic damage. Importantly, we report the maintenance of the functional (both hematological and immunological) integrity of the spleen at doses as high as $10 \mathrm{mg} / \mathrm{kg}$, although at the highest dose administered slight immunological variations were observed. Using confocal Raman mapping, as well as immunohistochemistry and conventional Raman spectroscopy in combination, to map the splenic distribution of GO, we identified that a subpopulation of splenic macrophages, known as the marginal zone macrophages, were the predominant cells responsible for bioaccumulating the material. Finally, using an array of techniques including Raman spectroscopy and TEM coupled with electron diffraction, we tracked the fate of the bioaccumulated GO over nine months and provide compelling evidence, down to the ultrastructural level, to suggest the in vivo biodegradation of GO to such an extent that the material lost its detectable graphitic crystalline structure. This further suggests that the initial accumulation of GO in the spleen was a transient event. This important result supports the development of thoroughly characterized GO sheets for biomedical technologies and is highly encouraging especially for systemic drug delivery purposes, where the biocompatibility and biodegradability of nanocarriers are a key advantage. ${ }^{103}$

\section{EXPERIMENTAL SECTION}

Graphene Oxide Preparation. The oxidation of graphite was based on a modified Hummers' method. ${ }^{86}$ Briefly, a mixture of $0.8 \mathrm{~g}$ of flake graphite (Graflake 9580, Brazil) and $0.4 \mathrm{~g}$ of sodium nitrate $\left(\mathrm{NaNO}_{3}\right)$ was maintained at approximately $0{ }^{\circ} \mathrm{C}$ using an ice bath. Then $18.4 \mathrm{~mL}$ of $96 \%$ sulfuric acid $\left(\mathrm{H}_{2} \mathrm{SO}_{4}\right)$ was added to the mixture while stirring, followed by the gentle addition of $2.4 \mathrm{~g}$ of potassium permanganate $\left(\mathrm{KMnO}_{4}\right)$. The mixture was taken from the ice bath. After $30 \mathrm{~min}$, the mixture increased in viscosity and resulted in the formation of a dark-colored paste. A volume of $37 \mathrm{~mL}$ of Milli- $\mathrm{QH}_{2} \mathrm{O}$ was added. An increase in temperature to $80^{\circ} \mathrm{C}$ was observed, and this continued until $98^{\circ} \mathrm{C}$. The temperature was maintained at $98^{\circ} \mathrm{C}$ for 30 $\mathrm{min}$. After this duration, the mixture was diluted with a volume of 112 $\mathrm{mL}$ of warm Milli-Q $\mathrm{H}_{2} \mathrm{O}$. A $12 \mathrm{~mL}$ aliquot of $30 \% \mathrm{H}_{2} \mathrm{O}_{2}$ was added subsequently. The suspension was centrifuged and pelleted repeatedly at $7690 \mathrm{~g}$ for $20 \mathrm{~min}$; the supernatant was then removed and replaced with Milli- $\mathrm{QH}_{2} \mathrm{O}$. This process was repeated until the acidic $\mathrm{pH}$ of the supernatant was neutralized $\left(\mathrm{pH} 7,20^{\circ} \mathrm{C}\right)$ and a viscous orange/brown gel layer of single-to-few-layer GO appeared on top of the graphite oxidation byproducts. This gel-like layer was carefully extracted with warm water to yield a dispersion of GO. A known volume of this aqueously dispersed material was freeze-dried, and the dry material weighed. This allowed the concentration of the extracted GO material to be determined. The concentration of the material was found to be 2.4 $\mathrm{mg} / \mathrm{mL}$. The aqueously dispersed GO was then subjected to ultrasonication for $5 \mathrm{~min}$ (VWR, 80W) to prepare the desired small sheet size GO. The internal batch reference of GO used in the present study is GO (f1s). Samples were characterized via AFM, TEM, selected area electron diffraction (SAED), ATR FT-IR, TGA, XPS, UV-vis, and fluorescence spectroscopy to confirm successful synthesis of single to few layer small GO sheets.

Atomic Force Microscopy. Sample preparation was completed on freshly cleaved mica, treated with $40 \mu \mathrm{L}$ of poly-L-lysine (SigmaAldrich, UK). The poly-L-lysine was used to present a positively charged surface that would allow the adhesion of GO. Aliquots $(10 \mu \mathrm{L})$ of GO $(100 \mu \mathrm{g} / \mathrm{mL})$ were transferred onto the mica-poly-L-lysine surface and left to adsorb for $2 \mathrm{~min}$. Unbound structures were removed by gentle rinsing with $2 \mathrm{~mL}$ of Milli- $\mathrm{QH}_{2} \mathrm{O}$ and left to dry at room temperature. A multimode atomic force microscope (Bruker, UK) was applied in tapping mode, in order to avoid damaging the samples, for height (trace and retrace) and amplitude measurements. Measurements were performed using an Otespa tapping mode tip (Bruker, UK). The following parameters were employed: scan rate, $1 \mathrm{~Hz}$; lines per scan, 512; integral gain, 1; proportional gain, 5; amplitude set point, $150 \mathrm{mV}$ (maintained approximately constant between all measurements). Scans were taken at 50,20,10,5, and $2 \mu \mathrm{m}$ (aspect ratio 1:1). Postimage processing was completed using the Bruker Nanoscope Analysis version 1.4 software (Bruker, UK) and included section analysis for measuring the cross-sectional height of samples.

Transmission Electron Microscopy for Material Characterization. A $20 \mu \mathrm{L}$ aliquot of sample $(200 \mu \mathrm{g} / \mathrm{mL})$ was placed on a carbon-coated copper grid (CF400-Cu) (Electron Microscopy Services, UK) and left to adsorb for 2 min. Filter paper (MerkMillipore, UK) was used to gently remove the excess dispersed material. Then samples were observed with a FEI Tecnai 12 BioTWIN microscope (FEI, NL) at an acceleration voltage of $100 \mathrm{kV}$. Images were taken with a Gatan Orius SC1000 CCD camera (Gatan, UK). For SAED of GO sheets, material samples was prepared as described above, however, on Quantifoil S 7/2 copper grids (Electron Microscopy Services, USA). SAED patterns were acquired on a FEI Talos 200X (FEI, Eindhoven, NL), operating at $80 \mathrm{kV}$ and using electron dose rates ranging between 45 and $84 \mathrm{e}^{-} \cdot \mathrm{A}^{-1} \mathrm{~s}^{-} 1$. This microscope was equipped with a FEI Ceta CMOS camera. Patterns were acquired from $0.5 \mu \mathrm{m}^{2}$ areas, corresponding to the $40 \mu \mathrm{m}$ selected-area aperture. An acquisition time of $1 \mathrm{~s}$ was used.

Raman Spectroscopy for Material Characterization. Samples were prepared for analysis by drop casting $20 \mu \mathrm{L}$ of GO $(100 \mu \mathrm{g} / \mathrm{mL})$ dispersion onto a glass slide. Samples were left to dry for at least $2 \mathrm{~h}$ at $37^{\circ} \mathrm{C}$. Spectra were collected using a DXR Raman microscope 
(Thermo Fisher Scientific, UK) using a $\lambda=633 \mathrm{~nm}$ laser. Spectra were considered between 250 and $3500 \mathrm{~cm}^{-1}$, enabling the visualization of the D and G scatter bands. Prior to the measurements, the Raman system was energy calibrated to a polystyrene reference material. The calibrated instrument had an energy resolution of $2.5 \mathrm{~cm}^{-1}$. Spectra were collected at a laser power of $0.4 \mathrm{~mW}$ with a magnification lens of $50 \times$ (numerical aperture: 0.75 ) with a $25 \mathrm{~s}$ exposure time and averaged over five locations. Raman spectra were corrected for tissue autofluorescence using a sixth-order polynomial baseline correction; all spectra were normalized to the $G$ peak for $I(D) / I(G)$ calculation using Origin Pro 8.5.1. software (Origin Lab, USA).

Attenuated Total Reflection Fourier Transform Infrared Spectroscopy. A drop of GO dispersion was placed into a Tensor 27 FTIR machine (Bruker, UK) and dried for $5 \mathrm{~min}$ at $60^{\circ} \mathrm{C}$ until a powder remained. Spectroscopic analysis was carried out between 750 and $4000 \mathrm{~cm}^{-1}$. Data processing was completed using OriginPro 8.5.1. software (Origin Lab, USA).

Thermogravimetric Analysis. Lyophilized GO (2 mg) was weighed into a ceramic crucible set at $25{ }^{\circ} \mathrm{C}$ in a TGA 400 thermogravimetric analyzer (PerkinElmer, UK). Samples were initially held at $100{ }^{\circ} \mathrm{C}$ for $5 \mathrm{~min}$ to reduce the presence of residual water. The temperature was then increased at a rate of $10^{\circ} \mathrm{C}$ per minute from 25 to $995^{\circ} \mathrm{C}$, with a nitrogen flow of $20 \mathrm{~mL} / \mathrm{min}$. Measurements were considered between 100 and $800{ }^{\circ} \mathrm{C}$ to avoid water interference. Data processing was completed using OriginPro 8.5.1. software (Origin Lab, USA).

X-ray Photoelectron Spectroscopy. The chemical composition of the GO sheets was studied by XPS at the NEXUS facility (the UK's National EPSRC XPS Users' Service, hosted by nanoLAB in Newcastleupon-Tyne). XPS spectra was recorded using a Thermo Theta Probe XPS spectrometer with a monochromatic Al K $\alpha$ source of $1486.68 \mathrm{eV}$. The survey XPS spectra were acquired with a pass energy (PE) of 200 $\mathrm{eV}$, a $1 \mathrm{eV}$ step size, and a $50 \mathrm{~ms}$ dwell time and averaged over five scans. The etching step was $90 \mathrm{~s}$. The high-resolution C 1s XPS spectra were acquired with a PE of $40 \mathrm{eV}$, a step size of $0.1 \mathrm{eV}$, and a $100 \mathrm{~ms}$ dwell time and averaged over 20 scans. Spectra from insulating samples were charge-corrected by shifting all peaks to the adventitious carbon $\mathrm{C} 1 \mathrm{~s}$ spectral component, with the binding energy set to $284.6 \mathrm{eV}$. The CasaXPS software was used to process the spectra acquired at NEXUS. Processing steps included the C 1s XPS spectral deconvolution and assignment of the different deconvoluted spectral components as per the binding energies at which they arise. These assignments were made in accordance with NIST's XPS databases: $\pi-\pi^{*}: 290-290.2, \mathrm{O}-\mathrm{C}=$ O: $289.7-288.2 \mathrm{eV}, \mathrm{C}=\mathrm{O}: 288.1-287.4 \mathrm{eV}, \mathrm{C}-\mathrm{O}: 286.8-286.2, \mathrm{C}-$ $\mathrm{C}$ and $\mathrm{C}=\mathrm{C}: 284.6 \mathrm{eV}$. The full width half-maximum of each deconvoluted peak, other than that of the $\pi-\pi^{*}$, was constrained to the same extent, and a Shirley background was taken. The peak for $\mathrm{C}-\mathrm{C} /$ $\mathrm{C}=\mathrm{C}$ was of an asymmetric line shape, while the rest were of the standard Gaussian-Lorentzian line shape.

UV/Visible Spectroscopy. The UV-vis absorbance spectra of GO were measured by a Varian Cary win UV 50 Bio spectrophotometer (Agilent Technologies, UK). The GO samples were diluted in water from 7.5 to $20 \mu \mathrm{L} / \mathrm{mL}$ prior to measurement in a $1 \mathrm{~mL}$ glass cuvette with a $1 \mathrm{~cm}$ path length. Dual-beam mode and baseline correction were used throughout the measurements to scan the peak wavelength and maximum absorbance between 200 and $600 \mathrm{~nm}$.

Fluorescence Spectroscopy. Fluorescence emission spectra of GO were measured over a concentration range between 75 and $200 \mu \mathrm{g} /$ $\mathrm{mL}$, using an LS-50B spectrofluorimeter (PerkinElmer, UK), with both excitation and emission slits set at $20 \mathrm{~nm}$. The excitation wavelength used was $525 \mathrm{~nm}$.

Animal Handling Procedures. Eight-week-old C57BL/6 mice $(18.1 \pm 0.7 \mathrm{~g})$ were obtained from Harlan (Oxfordshire, UK), allowed to acclimatize for 1 week, and maintained under a $12 \mathrm{~h}$ light-dark cycle at a steady temperature and humidity. Mice were allowed access to food and water ad libitum for the duration of the investigation. All experiments were conducted in accordance with the UK Home Office Code of Practice (1989) for the housing and care of animals in scientific procedures in accordance with prior approval from the UK Home Office (Project License Number: P6C826A12). For short-term splenic function and structural studies, mice $(n=3)$ were intravenously administered with GO $(2.5,5$, and $10 \mathrm{mg} / \mathrm{kg}$ ) or Dex $5 \%$ (negative control) and were culled for the different experiments after $24 \mathrm{~h}$ and 1 month. LPS (E. coli O127:B8, L4516-1MG; Sigma-Aldrich, UK) (5 $\mathrm{mg} / \mathrm{kg}$ ) at $24 \mathrm{~h}$ was used as the positive control. These mice were maintained for only $24 \mathrm{~h}$, since the mice showed symptoms of distress and were therefore culled at this time point. LPS is known to illicit inflammatory responses following injection and is commonly used as a positive control in this respect. Relevant to our study, LPS can induce increased levels of red blood cell deformity, pro-inflammatory cytokines, and apoptosis; ${ }^{41,62}$ this is expected to result in alterations to both structure and function of the spleen. Administration of LPS as a positive control, therefore, allowed us to compare and gauge the potential toxicological effects of GO on spleen structure and function. For longer term degradation studies, mice $(n=3)$ were administered with either $7.5 \mathrm{mg} / \mathrm{kg}$ or Dex 5\% (negative control). The mass concentrations of $\mathrm{GO}$ in the injection was $0.75 \mathrm{mg} / \mathrm{mL}$, corresponding to $150 \mu \mathrm{g}$ of GO per injection. Mice were then culled at different time points $(1,7,14,30,90,180$, and 270 days following the single administration) via being subject to terminal anesthesia followed by cervical dislocation. For all experiments, mice were continuously monitored and weighed every 4 days during the first month and weekly thereafter.

Spleen Histopathological Analysis. Spleens of mice were fixed with $4 \%$ paraformaldehyde and dehydrated through increasing concentrations of alcohol (ethanol 50-100\%) and embedded by paraffin wax. Sections of $5 \mu \mathrm{m}$ were cut on a microtome (Leica, UK), stained with hematoxylin and eosin stain $(\mathrm{H} \& \mathrm{E})$, coverslipped with resinous mounting media, and allowed to dry for $48 \mathrm{~h}$ at $37^{\circ} \mathrm{C}$. Images were collected using a $20 \times$ objective in a 3D Histech Panoramic 250 Flash slide scanner. Images were processed and analyzed using Pannoramic Viewer (http://www.3dhistech.com/) and Fiji/ImageJ software (version 1.5c; National Institutes of Health, USA). All three mice were examined per condition.

Blood Smear Analysis. Blood was collected from mice via cardiac puncture and immediately drawn into a capillary tube. One drop of blood (approximately $4 \mathrm{~mm}$ in diameter) was placed on a clean slide (near the end). The drop was spread by another glass slide placed at a $45^{\circ}$ angle and pressed into the drop of blood, allowing it to spread via capillary action. The slides were then fixed with cold methanol (precooled to $-20^{\circ} \mathrm{C}$ ) and allowed to dry at room temperature. The samples were stained by $\mathrm{H} \& \mathrm{E}$ stain and imaged as described above. Reticulocytes and abnormal and aged RBCs were considered as deviant RBCs, ${ }^{52-56,104}$ and their percentage of the total RBCs was calculated. More than 500 cells were counted for each mouse $(n=3$ for each group).

Perls' Persian Blue Analysis of Spleen Sections. Paraffinembedded sections of spleens were sectioned at $5 \mu \mathrm{m}$ and then dehydrated as described above. The sections were stained with a freshly prepared mixture of aqueous solutions of $20 \%$ hydrochloric acid and $10 \%$ potassium ferrocyanide trihydrate (Sigma-Aldrich, UK) at a volume ratio of $1: 1$, followed by counter staining with nuclear fast red $0.2 \%$ aqueous solution. The slides were dehydrated through $95 \%$ and $100 \%$ ethanol solutions, respectively, with two consecutive changes for each concentration. They were then coverslipped with resinous mounting media and left to dry overnight. Images were collected as described above. The percentage of blue pigmentation was analyzed by Fiji/ImageJ software (version 1.5c; National Institutes of Health, USA). This was obtained from three to four images from each mouse captured at $20 \times$ after setting a threshold ( $n=3$ mice per group).

Spleen Single-Cell Suspension Preparation. Half spleens were extracted from mice and placed immediately in RPMI 1640 media (Sigma-Aldrich, UK) supplemented with 10\% FBS (Gibco, Thermo Fisher Scientific, UK) and $1 \%$ penicillin and streptomycin (SigmaAldrich, UK). Single-cell suspensions were obtained by gently passing the spleens through a $100 \mu \mathrm{m}$ cell strainer (BD Falcon cell sieve). The cell suspension was centrifuged at $400 \mathrm{~g}$ for $5 \mathrm{~min}$, and the supernatant was discarded. The cells were resuspended in fresh media, and the contaminating RBCs were removed by adding 3-4 $\mathrm{mL}$ of red blood cell lysis buffer (Roche, UK) and allowed to react at $4{ }^{\circ} \mathrm{C}$ for $5 \mathrm{~min}$. The cell 
suspension was then centrifuged ( $400 \mathrm{~g}$ for $5 \mathrm{~min}$ ), and the cells were pelleted while the supernatant was discarded. The cell pellet was then resuspended and washed in fresh media twice. The splenocytes were counted using a cytometer, aliquoted, and further processed as needed.

T-Lymphocyte Counts by Flow Cytometry. Splenocytes were first preincubated with anti-CD16/32 antibodies at $2 \mu \mathrm{g} / \mathrm{mL}$ (eBioscience, UK, ref \#16-0161-85) for $20 \mathrm{~min}$ on ice, in order to block nonspecific binding sites. The cells were washed (centrifuged at $400 \mathrm{~g}$ for $5 \mathrm{~min}$ ) and then labeled with the antibody mixture of antiCD4-PE at $0.25 \mu \mathrm{g} / \mathrm{mL}$ (eBioscience, UK, ref \#12-0041-82) and antiCD8a at $0.25 \mu \mathrm{g} / \mathrm{mL}$. PerCP-Cy5.5 (eBioscience, UK, ref \#45-008182 ) was further incubated with the cells on ice for another $20 \mathrm{~min}$. Cells were then washed and resuspended in buffer (1\% sodium azide and $1 \%$ FBS in $1 \times$ PBS) for acquisition. Flow cytometry analysis was carried out using a BD FACSVerse flow cytometer (Becton Dickinson, Oxford, $\mathrm{UK})$. Single-color control samples were used to set compensation. PE and PerCE-Cy5.5 fluorescence was detected with 574/26 nm and 690/ $50 \mathrm{~nm}$ band-pass filters, respectively, after excitation with a $488 \mathrm{~nm}$ blue laser. Data were analyzed and statistics were generated using the FACSuite v1.6 software (Becton Dickinson, Oxford, UK).

Spleen Cytokine Gene Expression by RT-qPCR. An Aurum Total RNA minikit (Biorad, UK) was used to extract the total RNA of 2 $\times 10^{6}$ isolated splenocytes. The RNA concentration and quality were analyzed using UV spectrophotometry (BioPhotometer, Eppendorf, UK). cDNA synthesis was performed from $1 \mu \mathrm{g}$ of RNA sample with an iScript cDNA synthesis kit (Bio-Rad, UK) according to the manufacturer's instructions. The protocol for reverse transcription was set as follows: $25^{\circ} \mathrm{C}$ for $5 \mathrm{~min}, 42^{\circ} \mathrm{C}$ for $30 \mathrm{~min}, 85^{\circ} \mathrm{C}$ for $5 \mathrm{~min}$, and $4{ }^{\circ} \mathrm{C}$ for $5 \mathrm{~min}$. A $2 \mu \mathrm{L}$ amount of cDNA sample was used for each real-time qPCR reaction performed with iQ SYBR Green Supermix (Bio-Rad, UK). Experimental duplicates of each sample were run on a CFX-96 real time system (Bio-Rad, UK) with the following protocol: $95^{\circ} \mathrm{C}$ for $3 \mathrm{~min}$, one cycle; $95^{\circ} \mathrm{C}$ for $10 \mathrm{~s}, 60^{\circ} \mathrm{C}$ for $30 \mathrm{~s}$ : repeated for 40 cycles. Melt curve analysis was conducted at the end of the protocol to confirm amplification of a single product. $\beta$-Actin was used as a housekeeping gene, and gene expression levels were normalized to the Dex $5 \%$-injected control group. Primer sequences were as follows: $\beta$ actin, Fwd 5' GACCTCTATGCCAACACAGT $3^{\prime}$ and $\mathrm{Rv} 5^{\prime}$ AGTACTTGCGCTCAGGAGGA $3^{\prime}$; IL-6, Fwd 5' ATGGATGCTACCAAACTGGA $3^{\prime}$ and Rv $5^{\prime}$ CCTCTTGGTTGAAGATATGA 3'; TNF $\alpha$, Fwd 5' CAGACCCTCACACTCAGATCATCT 3' and Rv 5' CCTCCACTTGGTGGTTTGCTA 3'; IL-1 $\beta$, Fwd 5' GGACAGAATATCAACCAACAAGTGATA $3^{\prime}$ and $\mathrm{Rv} 5^{\prime}$ GTGTGCCGTCTTTCATTACACAG $3^{\prime}$; IL-10, Fwd 5' GGTTGCCAAGCCTTATCGGA $3^{\prime}$ and $\mathrm{Rv} 5^{\prime}$ ACCTGCTCCACTGCCTTGCT $3^{\prime}$; TGF- $\beta$, Fwd $5^{\prime}$ GACCAGCCGCCGCCGCAGG $3^{\prime}$ and $\mathrm{Rv} 5^{\prime}$ AGGGCTGTCTGGAGTCCTC 3'.

Confocal Raman Mapping of Tissue Sections. Mice were culled and spleens were immediately extracted and washed in $1 \times$ phosphate buffered saline (PBS) (Sigma-Aldrich, UK). One quarter of each extracted spleen was immediately transversely immersed into the optimal cutting temperature (O.C.T. compound, Tissue-Tek) media and then snap-frozen in isopropanol (Sigma-Aldrich, UK) precooled to liquid nitrogen temperatures. The spleens were cut into $5 \mu \mathrm{m}$ thick sections via cryomicrotomy (Leica, UK) and placed onto glass slides. The tissue sections were then fixed using $300 \mu \mathrm{L}$ of ice-cold methanol (Sigma-Aldrich, UK) for $10 \mathrm{~min}$. The sections were subsequently gently washed in $1 \times$ PBS twice in order to remove the O.C.T. compound. Milli-Q water was used to remove any salt crystals from the PBS. The sample was redoused with $300 \mu \mathrm{L}$ of ice-cold methanol and dried for $1 \mathrm{~h}$ at $37^{\circ} \mathrm{C}$ to dehydrate the sample. Raman scanning was completed on regions of the spleen tissue including the red and white pulp regions. Raman scanning was completed using a polystyrene calibrated DXRxi Raman mapping system (Thermo Scientific, UK) using the following conditions: $\lambda=633 \mathrm{~nm}, 1 \mathrm{~mW}$, objective $50 \times$ (numerical aperture: 0.75 ), pixel size $=3 \mu \mathrm{m}$. The software was used to generate Raman correlation maps based on the correlation of the acquired signal with the spectra of the starting material shown in Figure 1C. The instrument had an energy resolution of $2.5 \mathrm{~cm}^{-1}$. Dex $5 \%$-treated animals were analyzed in the same way to ensure no cross contamination as a quality check.

Immunofluorescence with Raman Spectroscopy. Mice were culled, and the spleens were immediately extracted and washed in $1 \times$ PBS (Sigma-Aldrich, UK). One quarter of the spleen was immediately transversely immersed into the O.C.T. compound and snap-frozen in isopropanol (Sigma-Aldrich, UK) that was precooled to liquid-nitrogen temperatures. The spleens were next sectioned into $5 \mu \mathrm{m}$ sections via cryomicrotomy, and the sections were collected onto glass slides (VWR, UK). Afterward, the tissue sections were fixed using $300 \mu \mathrm{L}$ of ice-cold methanol (Sigma-Aldrich, UK) for $10 \mathrm{~min}$. The methanol was removed, and the fixed tissues were incubated in blocking buffer $(1 \%$ bovine serum albumin (fraction v, Sigma-Aldrich, UK), 0.1\% Triton $\mathrm{X} 100$ in $1 \times \mathrm{PBS}$ ) for $1 \mathrm{~h}$ in a humidification chamber. Tissue sections were washed in a washing buffer that consisted of $0.1 \%$ Triton X100 in $1 \times$ PBS, three times for $5 \mathrm{~min}$ each. The washing buffer was removed, and the tissue was incubated with the biotinylated Anti-SIGN Related 1 antibody [ER-TR9] (\#AB51819, Abcam, UK) diluted in blocking buffer to $3.3 \mu \mathrm{g} / \mathrm{mL}$ for $2 \mathrm{~h}$ at room temperature in a humidification chamber. The antibody solution was removed, and the tissue sections were gently washed with the washing buffer three times for 5 min each. The tissue sections were incubated with the revealing agent, Fluorescein Avidin DCS (Vector Laboratories, UK), which was diluted to $22 \mu \mathrm{g} / \mathrm{mL}$ with HEPES-buffered saline ( $\mathrm{pH} 8.2,20^{\circ} \mathrm{C}$ ), for $2 \mathrm{~h}$ in a humidification chamber. The tissue was then washed with washing buffer, and excess liquid was removed using a cotton bud. The tissue sections were coverslipped with Prolong gold antifade including DAPI (Thermo Fisher Scientific, UK). The sample was left in the dark at room temperature for a $24 \mathrm{~h}$ period. Fluorescence microscopy was completed, and the regions where ERTR-9 staining was detected were marked on a customized grid. Controls consisting of either the revealing agent (Fluorescein Avidin) alone without biotinylated antibody (to ensure no signal was originating from the unspecific binding of the revealing agent) or tissues from animals treated with dextrose 5\% were included in this experiment, in order to exclude false-positive readings. The coverslips were later gently removed by incubating the slides in $1 \times$ PBS overnight at room temperature. Following this treatment, the coverslips could be removed via gravity; care was taken not to damage the fixed tissue. The exposed tissues were gently washed with Milli-Q water and left to dry at $37^{\circ} \mathrm{C}$ for $1-2 \mathrm{~h}$. Using the marked grids the same regions identified by fluorescence microscopy were analyzed by a "point-and-shoot" polystyrene calibrated DXR Raman microscope (Thermo Fisher Scientific, UK) using a laser at $\lambda=633 \mathrm{~nm}, 0.4 \mathrm{~mW}$, $50 \times$ (numerical aperture of 0.75 ) and an exposure time of $25 \mathrm{~s}$ and averaged over three readings; the energy resolution of the instrument was $2.5 \mathrm{~cm}^{-1}$. This allowed the colocalization of the Raman signature of $\mathrm{GO}$ with the immunofluorescence signal of ERTR-9-positive marginal zone macrophages. The spleens of at least three mice, with two or more splenic sections, were imaged.

Fluorescence-Activated Cell Sorting with Raman Spectroscopy. A single-cell suspension of splenocytes was obtained as described above. The isolated cells were then stained with the relevant antibodies mentioned below as per the manufacturer's instructions. FACS was then performed on live cells on a BD Influx cell sorter (BD Biosciences, Oxford, UK). Fluorescently conjugated antibodies (Miltenyi Biotec Limited, UK) were excited, and their emission was collected under the following conditions: CD45-VioBlue, violet laser, band-pass 460/50; F4/80-v770-PE, yellow-green laser, 750LP; CD11c-FITC, blue laser, band-pass 530/40; CD209-PE, yellow-green laser, band-pass 585/29; CD169b, red laser, band-pass 670/30. Cells were gated on an initial scatter gate to exclude debris. Lymphocytes were identified as $\mathrm{CD}^{+} 5^{+} /$ side scatter low and granulocytes were $\mathrm{CD}_{4} 5^{+} /$side scatter high. F4/ $80^{+} / \mathrm{CD} 11 \mathrm{c}^{-}$macrophages were gated from the granulocyte gate and $\mathrm{CD} 11 \mathrm{c}^{+} / \mathrm{F} 4 / 80^{-}$dendritic cells were gated from this population too. The $\mathrm{CD} 209^{+}$and $\mathrm{CD} 169 \mathrm{~b}^{+}$cells were identified as being $\mathrm{F} 4 / 80^{-}$/ $\mathrm{CD} 11 \mathrm{c}^{-}$and identified by plotting them against each other. Baseline voltages were set using unlabeled cells, and positive populations were identified using full minus one (FMO) controls. Cells were filtered through a $50 \mu \mathrm{m}$ mesh prior to being sorted through a $100 \mu \mathrm{m}$ diameter nozzle at 20 PSI pressure, which generated a drop drive frequency of 38 
$\mathrm{kHz}$. Sort side streams were optimized to enable five separate populations to be collected simultaneously from each individual sample. Up to 20000 cells were collected depending on the frequency of the cell subpopulation in the sample. The event rate was maintained at 2000-3000 events per second to minimize aberrant droplet formation and ensure a high degree of purity in the sorted cells. Cells were collected into $1.5 \mathrm{~mL}$ tubes containing $1 \times \mathrm{PBS}$ and then deposited onto glass slides via a Cytospin apparatus using a centrifuge set to $350 \mathrm{~g}$. The cells were fixed onto the glass slide with a drop of ice cold methanol. Once dry, the sample was analyzed via Raman microscopy using a DXR Raman microscope (Thermo Fisher Scientific, UK) calibrated to polystyrene with an energy resolution of $2.5 \mathrm{~cm}^{-1}$. Measurements used a laser at $\lambda=633 \mathrm{~nm}, 0.4 \mathrm{~mW}, 50 \times$ (numerical aperture of 0.75 ), and an exposure time of $25 \mathrm{~s}$ and averaged over three readings. The percentage of scanned cells in which GO was detected was determined at each time point, $n=$ three mice $\times 20$ cells. Cells isolated from Dex $5 \%$-treated mice were processed in the same way and scanned to ensure there was no cross contamination of GO between samples.

TUNEL Staining. Spleen sections were embedded in paraffin wax, sectioned to $5 \mu \mathrm{m}$ thickness on a microtome (Leica, UK), and placed on glass slides. The sections then underwent deparafinization via two immersions in xylene for $5 \mathrm{~min}$ each, followed by washing in $100 \%$ methanol for $5 \mathrm{~min}$. The samples were subsequently rehydrated by passing them through a series of decreasing concentrations of alcohol concentrations $(100 \%, 95 \%, 85 \%, 70 \%, 50 \%)$ for $3 \mathrm{~min}$ at each concentration. The sections were further washed in $0.85 \% \mathrm{NaCl}$ for 5 min. The rehydrated sections were fixed in $4 \%$ formaldehyde (ref \#28908; Thermo Fisher Scientific, UK) for $15 \mathrm{~min}$. The remaining formaldehyde was then removed by washing in PBS $1 \times$ (Sigma-Aldrich, UK) twice for 5 min each. The excess PBS was removed gently with filter paper, being careful to not touch the sections. The glass slides with their fixed sections were then placed on a flat surface, and $10 \mu \mathrm{L}$ of a 20 $\mu \mathrm{g} / \mathrm{mL}$ proteinase- $\mathrm{K}$ solution was placed on each tissue section. The slides were left with the proteinase K solution for an optimized time of 8 $\mathrm{min}$. Proteinase K was removed by washing with PBS for $5 \mathrm{~min}$. Then the tissue was covered with $100 \mu \mathrm{L}$ of equilibrium buffer and left to equilibrate for $5 \mathrm{~min}$. The equilibrium buffer was removed, and $50 \mu \mathrm{L}$ of rTdT incubation buffer was added onto each slide and left for $60 \mathrm{~min}$ in a humidification chamber at $37{ }^{\circ} \mathrm{C}$. The slides were next immersed in physiological saline (sodium chloride) $2 \times$ to terminate the reaction. The slides were then washed in PBS $1 \times$ (Sigma, UK) twice for $5 \mathrm{~min}$ and then washed twice in Milli- $\mathrm{Q}$ water for another $5 \mathrm{~min}$ each. The slides were, thereafter, incubated in $4 \%$ Sudan black (in ethanol) for 10 min to eliminate RBC-derived fluorescence, followed by washing seven times in PBS $1 \times$ (Sigma, UK) for 3 min each and three washes in Milli$\mathrm{Q}$ water for $3 \mathrm{~min}$ each. The slides were coverslipped with Prolong gold antifade including DAPI (Thermo Fisher Scientific, UK) and left at room temperature in the dark for $24 \mathrm{~h}$. Images were collected using a $20 \times$ objective in a 3D Histech Panoramic 250 Flash slide scanner. Images were processed and analyzed using Pannoramic Viewer (http:// www.3dhistech.com/) and Fiji/ImageJ software (version 1.5c; National Institutes of Health, USA). Three mice were examined per condition. A total of five images of $300 \mu \mathrm{m}^{2}$ were analyzed per mouse. The number of TUNEL-positive cells was blindly counted by three independent investigators, and the counts of the three individuals were averaged for each image.

Raman Spectroscopy on Homogenized Spleens. For each time point analyzed, a quarter of the extracted and washed individual murine spleens were homogenized mechanically onto a glass slide and left to dry for 30-60 min at room temperature and pressure. This was completed in order to assess the state of the overall GO content of the spleen, instead of cell-specific content. Raman spectroscopy was performed on the tissue homogenates using a polystyrene calibrated DXR Raman microscope (Thermo Fisher Scientific, UK) using a $\lambda=$ $633 \mathrm{~nm}$ laser a $50 \times$ objective lens (numerical aperture of 0.75 ) and a laser power of $0.4 \mathrm{~mW}$ with an exposure time of $25 \mathrm{~s}$. The energy resolution was $2.5 \mathrm{~cm}^{-1}$. Raman scattering signals were acquired in at least 10 different regions per mouse with three biological replicas. Raman spectra were corrected for tissue autofluorescence using a sixth- order polynomial baseline correction, and the ratio of intensity of the $\mathrm{D}$ and $G$ peaks, $I(D) / I(G)$, was calculated and averaged for $n=10$ spectra for each of the three mice. We also scanned Dex 5\%-treated animals in the same way to ensure no cross contaminations as a quality check.

Histological Marginal Zone Analysis. For each time point in the degradation study, a quarter of the spleen was fixed with $4 \%$ paraformaldehyde and dehydrated through increasing concentrations of ethanol (50-100\%) and embedded in paraffin wax. Sections of $5 \mu \mathrm{m}$ thickness were cut and collected onto glass slides and then stained with $\mathrm{H} \& \mathrm{E}$ stain. The stained sections were then coverslipped with resinous mounting media and allowed to dry for $48 \mathrm{~h}$ at $37^{\circ} \mathrm{C}$. Images were collected using a $20 \times$ objective and a 3D Histech Panoramic 250 Flash slide scanner. Images were processed and analyzed to determine the average number of dark regions in the splenic marginal zone $(n=5$ marginal zones for each of the three mice) using Panoramic Viewer (http://www.3dhistech.com/) and Fiji/ImageJ software (version 1.5c; National Institutes of Health, USA).

TEM on Splenic Tissue Sections. For each time point analyzed, a quarter of each of the extracted and washed murine spleens was fixed in paraformaldehyde $(4 \%(\mathrm{w} / \mathrm{v}))$ /glutaraldehyde $(2.5 \%(\mathrm{w} / \mathrm{v}))$ (SigmaAldrich, UK) for $24 \mathrm{~h}$. Following fixation, specimens were cut into 2-3 $\mathrm{mm}$ blocks using a sterile surgical blade. Each specimen was washed several times with deionized water, submitted to a second fixation with reduced osmium tetroxide $\left(\mathrm{OsO}_{4}\right)$ (Agar Scientific, UK) for $90 \mathrm{~min}$, then rinsed with deionized water and dehydrated through a series of concentration-graded ethanol (Thermo Fisher Scientific, UK) solutions, $30 \%, 50 \%, 70 \%, 90 \%$, and $100 \%$. The specimens were incubated at each concentration for $15 \mathrm{~min}$; dilutions were made in Milli-Q water. This was followed by the incubation of the specimen in $100 \%$ acetone (Thermo Fisher Scientific, UK) for $15 \mathrm{~min}$. Each specimen was infiltrated with increasing concentrations of polypropylene TAAB 812 hard resin (TAAB Laboratories Ltd., UK) (25\%, 50\%, $75 \%$, and $100 \%$, using acetone as the diluent) for $12 \mathrm{~h}$ at each grade. Next, specimens were left in $100 \%$ resin for a further $6 \mathrm{~h}$ at room temperature. Specimens were, thereafter, orientated in the embedding mold filled with fresh $100 \%$ resin, such that transversal sectioning of the spleen sample would be possible. The resin (with the orientated sample) was then cured at $60{ }^{\circ} \mathrm{C}$ for $48 \mathrm{~h}$ to allow resin polymerization. TEM imaging was performed on ultrathin sections (approximately 40$70 \mathrm{~nm}$ thickness) obtained using an Ultracut $\mathrm{E}$ ultramicrotome (Reichert-Jung, Austria) and a diamond knife (Diatome $45^{\circ}$, Leica, UK). Ultrathin sections were collected onto coatless 200-mesh thin copper $3.05 \mathrm{~mm}$ grids (Electron Microscopy Services, USA) and observed under a FEI Tecnai T-12 BioTWIN TEM (FEI, Eindhoven, NL) equipped with an Orius CCD SC100 camera (Gatan, UK) at 100 $\mathrm{kV}$. The use of this microscope and grids allowed efficient observation of the whereabouts and tracking of the GO within tissue. We also scanned Dex 5\%-treated animals in the same way to ensure no cross contamination as a quality check.

Electron Diffraction of GO in Tissue Sections. Tissues were fixed and resin-embedded, and ultrathin sections were prepared for TEM, as described above. In this experiment, the ultrathin sections were collected onto Quantifoil S 7/2 copper grids (Electron Microscopy Services, USA). TEM and SAED shown in Figures 5A-iv, S13, and S14 were performed on a FEI Talos 200X (FEI, Eindhoven, $\mathrm{NL}$ ) operating at $80 \mathrm{kV}$ and using electron dose rates ranging between 45 and $84 \mathrm{e}^{-} \cdot \mathrm{A}^{-1} \mathrm{~s}^{-1}$. TEM images and SAED patterns were acquired using a FEI Ceta CMOS camera on an area of $3.14 \times 10^{-2}$ and $0.5 \mu \mathrm{m}^{2}$ corresponding to the selected-area apertures of 10 and $40 \mu \mathrm{m}$, respectively. An acquisition time of $1 \mathrm{~s}$ was used for the collection of TEM images and SAED patterns. However, for the acquisition of SAED patterns with a $10 \mu \mathrm{m}$ selected-area aperture, the acquisition time was set to $8 \mathrm{~s}$.

Statistical Analysis. All experimental data are represented as mean \pm standard error (SE) or mean \pm standard deviation (SD) as stated in each section, with at least $n=3,4$. Statistical significance was determined by the Kruskal-Wallis nonparametric test with Dunn's posthoc test or a Mann-Whitney U test for pairwise comparisons where appropriate. For RT-qPCR data Levene's test for homogeneity of variances was performed, if it showed significance $(p<0.05)$; then 
Welch ANOVA and a Games-Howell's posthoc test were performed. SPSS software, version 22.0, was used to perform this analysis. In all experiments, probability values of $<0.05$ were considered significant.

\section{ASSOCIATED CONTENT}

\section{SI Supporting Information}

The Supporting Information is available free of charge at https://pubs.acs.org/doi/10.1021/acsnano.0c03438.

Tables providing information regarding statistical robustness of the results presented in Figures 4C,D and 5B,C; figures presenting additional physicochemical characterization data of starting GO material, including FT-IR, TGA, XPS, fluorescence, and absorbance; additional data related to the analysis of the structure and function of the spleen following GO administration; 9-month growth curve of mice administered with GO or Dex 5\%; information on the abundance of GO in cells of the spleen, determined by FACS; images of TUNEL staining of murine sections over 9 months; additional information regarding the biodegradation of $\mathrm{GO}$, including additional histological images, Raman spectra, TEM micrographs, and SAED diffractograms; data regarding physicochemical characterization of GO material incubation in water at $37^{\circ} \mathrm{C}$ in the dark for 9 months (PDF)

\section{AUTHOR INFORMATION}

\section{Corresponding Authors}

Cyrill Bussy - Nanomedicine Lab, National Graphene Institute and Faculty of Biology, Medicine \& Health, The University of Manchester, Manchester M13 9PT, United Kingdom; 구 orcid.org/0000-0001-8870-443X; Email: cyrill.bussy@ manchester.ac.uk

Kostas Kostarelos - Nanomedicine Lab, National Graphene Institute and Faculty of Biology, Medicine \& Health, The University of Manchester, Manchester M13 9PT, United Kingdom; Catalan Institute of Nanoscience and Nanotechnology (ICN2), Barcelona 08193, Spain; 이이이.org/0000-00022224-6672; Email: kostas.kostarelos@manchester.ac.uk

\section{Authors}

Leon Newman - Nanomedicine Lab, National Graphene Institute and Faculty of Biology, Medicine \& Health, The University of Manchester, Manchester M13 9PT, United Kingdom

Dhifaf A. Jasim - Nanomedicine Lab, National Graphene Institute and Faculty of Biology, Medicine \& Health, The University of Manchester, Manchester M13 9PT, United Kingdom

Eric Prestat - Department of Materials, School of Natural Sciences, The University of Manchester, Manchester M13 9PL, United Kingdom

Neus Lozano - Nanomedicine Lab, National Graphene Institute and Faculty of Biology, Medicine \& Health, The University of Manchester, Manchester M13 9PT, United Kingdom; Catalan Institute of Nanoscience and Nanotechnology (ICN2), Barcelona 08193, Spain

Irene de Lazaro - Nanomedicine Lab, National Graphene Institute and Faculty of Biology, Medicine \& Health, The University of Manchester, Manchester M13 9PT, United Kingdom; (1) orcid.org/0000-0002-2775-0173

Yein Nam - Nanomedicine Lab, National Graphene Institute and Faculty of Biology, Medicine \& Health, The University of Manchester, Manchester M13 9PT, United Kingdom
Bakri M. Assas - Lydia Becker Institute of Immunology and Inflammation, and Division of Infection, Immunity and Respiratory Medicine, School of Biological Sciences, Faculty of Biology, Medicine and Health, The University of Manchester, Manchester M13 9PT, United Kingdom; Department of Immunology, Faculty of Applied Sciences, King Abdulaziz University, Jeddah 21589, Saudi Arabia

Joanne Pennock - Lydia Becker Institute of Immunology and Inflammation, and Division of Infection, Immunity and Respiratory Medicine, School of Biological Sciences, Faculty of Biology, Medicine and Health, The University of Manchester, Manchester M13 9PT, United Kingdom

Sarah J. Haigh - Department of Materials, School of Natural Sciences, The University of Manchester, Manchester M13 9PL, United Kingdom; 이이이.org/0000-0001-5509-6706

Complete contact information is available at:

https://pubs.acs.org/10.1021/acsnano.0c03438

\section{Author Contributions}

L.N. and D.J. designed, planned, performed most of the experimental work and data analysis, and drafted the manuscript. E.P. performed and assisted in the analysis of TEM and electron diffraction of GO in tissue sections. N.L. prepared the GO samples and helped in the physicochemical characterization of the samples. I.dL. performed the RT-qPCR experiment and data analysis. Y.N. assisted in the TUNEL staining of the spleen tissues. M.B.A. helped perform and gave advice on spleen cell sorting and spleen cytokine extractions. J.P. helped in the initial stages of the project with planning the spleen cell experiments, extractions, and flow cytometry. S.J.H. provided guidance on TEM experiments and discussed the findings. C.B. and K.K. conceptualized the study, designed, planned, and discussed the findings, reviewed and edited the manuscript, and overall supervised the work.

\section{Author Contributions}

${ }^{\#}$ L. Newman and D.A. Jasim contributed equally to this work.

\section{Notes}

The authors declare no competing financial interest.

\section{ACKNOWLEDGMENTS}

This work was partially supported by the EPSRC NOWNANO DTC program and grants EP/K016946/1 and EP/M010619/1. This work has received funding from the European Union's Horizon 2020 Research and Innovation Programme under Grant Agreement numbers GrapheneCore1 (696656) and GrapheneCore2 (785219). D.J. and K.K. would like to acknowledge the support by the UKRI, EPSRC from the Programme Grant 2D-Health (EP/P00119X/1). The DTRA, USA (grant HDTRA1-12-1-0013), is also acknowledged for partial support. The authors would like to acknowledge the staff in the Faculty of Biology, Medicine and Health EM Facility, particularly Dr. Aleksandr Mironov and Ms. Samantha Forbes, for their expertise and assistance, and the Wellcome Trust for equipment grant support to the EM Facility. The University of Manchester Bioimaging Facility microscopes used in this study were purchased with grants from the BBSRC, Wellcome Trust, and the University of Manchester Strategic Fund. The authors wish to acknowledge Mr. R. Meadows from the Bioimaging Facility. The authors are also thankful to Mr. P. Walker, from the Histology Facility, University of Manchester, for his expert advice and assistance in tissue histology. The authors also thank 
Dr. N. Hodson from the Bio-AFM Facility for assistance and advice regarding the AFM instrumentation.

\section{REFERENCES}

(1) Novoselov, K. S.; Falko, V. I.; Colombo, L.; Gellert, P. R.; Schwab, M. G.; Kim, K. A Roadmap for Graphene. Nature 2012, 490, 192-200.

(2) Kostarelos, K.; Novoselov, K. S. Graphene Devices for Life. Nat. Nanotechnol. 2014, 9, 744-745.

(3) Sun, X.; Liu, Z.; Welsher, K.; Robinson, J. T.; Goodwin, A.; Zaric, S.; Dai, H. Nano-Graphene Oxide for Cellular Imaging and Drug Delivery. Nano Res. 2008, 1, 203-212.

(4) Plachá, D.; Jampilek, J. Graphenic Materials for Biomedical Applications. Nanomaterials 2019, 9, 1758.

(5) Kostarelos, K.; Novoselov, K. S. Materials Science. Exploring the Interface of Graphene and Biology. Science 2014, 344, 261-263.

(6) Girish, C. M.; Sasidharan, A.; Gowd, G. S.; Nair, S.; Koyakutty, M. Confocal Raman Imaging Study Showing Macrophage Mediated Biodegradation of Graphene In Vivo. Adv. Healthcare Mater. 2013, 2, $1489-500$.

(7) Yang, K.; Wan, J.; Zhang, S.; Zhang, Y.; Lee, S.-T.; Liu, Z. In Vivo Pharmacokinetics, Long-Term Biodistribution, and Toxicology of Pegylated Graphene In Mice. ACS Nano 2011, 5, 516-522.

(8) Bussy, C.; Jasim, D.; Lozano, N.; Terry, D.; Kostarelos, K. The Current Graphene Safety Landscape - A Literature Mining Exercise. Nanoscale 2015, 7, 6432-6435.

(9) Jasim, D. A.; Menard-Moyon, C.; Begin, D.; Bianco, A.; Kostarelos, K. Tissue Distribution and Urinary Excretion of Intravenously Administered Chemically Functionalized Graphene Oxide Sheets. Chem. Sci. 2015, 6, 3952-3964.

(10) Aichele, P.; Zinke, J.; Grode, L.; Schwendener, R. A.; Kaufmann, S. H.; Seiler, P. Macrophages of the Splenic Marginal Zone are Essential for Trapping of Blood-Borne Particulate Antigen but Dispensable for Induction of Specific T Cell Responses. J. Immunol. 2003, 171, 11481155.

(11) Liu, D.; Mori, A.; Huang, L. Large Liposomes Containing Ganglioside GM1 Accumulate Effectively In Spleen. Biochim. Biophys. Acta, Biomembr. 1991, 1066, 159-165.

(12) Jasim, D. A.; Boutin, H.; Fairclough, M.; Ménard-Moyon, C.; Prenant, C.; Bianco, A.; Kostarelos, K. Thickness of Functionalized Graphene Oxide Sheets Plays Critical Role In Tissue Accumulation and Urinary Excretion: A Pilot Pet/Ct Study. Appl. Mater. Today 2016, 4, 24-30.

(13) Mebius, R. E.; Kraal, G. Structure and Function of the Spleen. Nat. Rev. Immunol. 2005, 5, 606-616.

(14) Zhu, J.; Paul, W. E. CD4 T Cells: Fates, Functions, and Faults. Blood 2008, 112, 1557-1569.

(15) Harty, J. T.; Tvinnereim, A. R.; White, D. W. CD8+ T Cell Effector Mechanisms In Resistance To Infection. Annu. Rev. Immunol. 2000, 18, 275-308.

(16) Wick, P.; Louw-Gaume, A. E.; Kucki, M.; Krug, H. F.; Kostarelos, K.; Fadeel, B.; Dawson, K. A.; Salvati, A.; Vázquez, E.; Ballerini, L.; Tretiach, M.; Benfenati, F.; Flahaut, E.; Gauthier, L.; Prato, M.; Bianco, A. Classification Framework for Graphene-Based Materials. Angew. Chem., Int. Ed. 2014, 53, 7714-7718.

(17) Kurapati, R.; Russier, J.; Squillaci, M. A.; Treossi, E.; MénardMoyon, C.; Del Rio-Castillo, A. E.; Vazquez, E.; Samorì, P.; Palermo, V.; Bianco, A. Dispersibility-Dependent Biodegradation of Graphene Oxide By Myeloperoxidase. Small 2015, 11, 3985-3994.

(18) Kotchey, G. P.; Allen, B. L.; Vedala, H.; Yanamala, N.; Kapralov, A. A.; Tyurina, Y. Y.; Klein-Seetharaman, J.; Kagan, V. E.; Star, A. The Enzymatic Oxidation of Graphene Oxide. ACS Nano 2011, 5, 20982108.

(19) Newman, L.; Lozano, N.; Zhang, M.; Iijima, S.; Yudasaka, M.; Bussy, C.; Kostarelos, K. Hypochlorite Degrades 2D Graphene Oxide Sheets Faster Than 1D Oxidised Carbon Nanotubes and Nanohorns. npj 2D Mater. Appl. 2017, 1, 39.

(20) Bai, H.; Jiang, W.; Kotchey, G. P.; Saidi, W. A.; Bythell, B. J.; Jarvis, J. M.; Marshall, A. G.; Robinson, R. A.; Star, A. Insight Into the
Mechanism of Graphene Oxide Degradation Via the Photo-Fenton Reaction. J. Phys. Chem. C 2014, 118, 10519-10529.

(21) Zhou, X.; Zhang, Y.; Wang, C.; Wu, X.; Yang, Y.; Zheng, B.; Wu, H.; Guo, S.; Zhang, J. Photo-Fenton Reaction of Graphene Oxide: A New Strategy To Prepare Graphene Quantum Dots for DNA Cleavage. ACS Nano 2012, 6, 6592-6599.

(22) Xing, W.; Lalwani, G.; Rusakova, I.; Sitharaman, B. Degradation of Graphene By Hydrogen Peroxide. Part. Part. Syst. Charact. 2014, 31, $745-750$.

(23) Lalwani, G.; Xing, W.; Sitharaman, B. Enzymatic Degradation of Oxidized and Reduced Graphene Nanoribbons By Lignin Peroxidase. J. Mater. Chem. B 2014, 2, 6354-6362.

(24) Ding, Y.; Tian, R.; Yang, Z.; Chen, J.; Lu, N. NADPH OxidaseDependent Degradation of Single-Walled Carbon Nanotubes In Macrophages. J. Mater. Sci.: Mater. Med. 2017, $28,7$.

(25) Elgrabli, D.; Dachraoui, W.; Marmier, H. d.; Ménard-Moyon, C.; Bégin, D.; Bégin-Colin, S.; Bianco, A.; Alloyeau, D.; Gazeau, F. Intracellular Degradation of Functionalized Carbon Nanotube/Iron Oxide Hybrids Is Modulated By Iron Via Nrf2 Pathway. Sci. Rep. 2017, 7, 40997.

(26) Lu, N.; Li, J.; Tian, R.; Peng, Y.-Y. Binding of Human Serum Albumin to Single-Walled Carbon Nanotubes Activated Neutrophils To Increase Production of Hypochlorous Acid, the Oxidant Capable of Degrading Nanotubes. Chem. Res. Toxicol. 2014, 27, 1070-1077.

(27) Jasim, D. A.; Murphy, S.; Newman, L.; Mironov, A.; Prestat, E.; McCaffrey, J.; Ménard-Moyon, C.; Rodrigues, A. F.; Bianco, A.; Haigh, S.; Lennon, R.; Kostarelos, K. The Effects of Extensive Glomerular Filtration of Thin Graphene Oxide Sheets On Kidney Physiology. ACS Nano 2016, 10, 10753-10767.

(28) Rodrigues, A. F.; Newman, L.; Lozano, N.; Mukherjee, S. P.; Fadeel, B.; Bussy, C.; Kostarelos, K. A Blueprint for the Synthesis and Characterisation of Thin Graphene Oxide With Controlled Lateral Dimensions for Biomedicine. 2D Mater. 2018, 5, No. 035020.

(29) Georgakilas, V.; Otyepka, M.; Bourlinos, A. B.; Chandra, V.; Kim, N.; Kemp, K. C.; Hobza, P.; Zboril, R.; Kim, K. S. Functionalization of Graphene: Covalent and Non-Covalent Approaches. Chem. Rev. 2012, $112,6156-6214$.

(30) Vacchi, I. A.; Spinato, C.; Raya, J.; Bianco, A.; Menard-Moyon, C. Chemical Reactivity of Graphene Oxide Towards Amines Elucidated By Solid-State NMR. Nanoscale 2016, 8, 13714-13721.

(31) Bianco, A.; Cheng, H.-M.; Enoki, T.; Gogotsi, Y.; Hurt, R. H.; Koratkar, N.; Kyotani, T.; Monthioux, M.; Park, C. R.; Tascon, J. M. D.; Zhang, J. All In the Graphene Family - A Recommended Nomenclature for Two-Dimensional Carbon Materials. Carbon 2013, $65,1-6$.

(32) Ilium, L.; Davis, S. S.; Wilson, C. G.; Thomas, N. W.; Frier, M.; Hardy, J. G. Blood Clearance and Organ Deposition of Intravenously Administered Colloidal Particles. The Effects of Particle Size, Nature and Shape. Int. J. Pharm. 1982, 12, 135-146.

(33) Bussy, C.; Ali-Boucetta, H.; Kostarelos, K. Safety Considerations for Graphene: Lessons Learnt From Carbon Nanotubes. Acc. Chem. Res. 2013, 46, 692-701.

(34) Jasim, D.; Lozano, N.; Kostarelos, K. Synthesis of Few-Layered, High-Purity Graphene Oxide Sheets From Different Graphite Sources for Biology. 2D Mater. 2016, 3, No. 014006.

(35) Figueiredo, J. L.; Pereira, M. F. R.; Freitas, M. M. A.; Órfão, J. J. M. Modification of the Surface Chemistry of Activated Carbons. Carbon 1999, 37, 1379-1389.

(36) Eigler, S.; Dotzer, C.; Hirsch, A.; Enzelberger, M.; Müller, P. Formation and Decomposition of $\mathrm{CO}_{2}$ Intercalated Graphene Oxide. Chem. Mater. 2012, 24, 1276-1282.

(37) Xu, Y.; Bai, H.; Lu, G.; Li, C.; Shi, G. Flexible Graphene Films Via the Filtration of Water-Soluble Noncovalent Functionalized Graphene Sheets. J. Am. Chem. Soc. 2008, 130, 5856-5857.

(38) Raghav, N.; Chakraborty, S.; Maiti, P. K. Molecular Mechanism of Water Permeation In a Helium Impermeable Graphene and Graphene Oxide Membrane. Phys. Chem. Chem. Phys. 2015, 17, 20557-20562. 
(39) Vranic, S.; Rodrigues, A. F.; Buggio, M.; Newman, L.; White, M. R. H.; Spiller, D. G.; Bussy, C.; Kostarelos, K. Live Imaging of LabelFree Graphene Oxide Reveals Critical Factors Causing OxidativeStress-Mediated Cellular Responses. ACS Nano 2018, 12, 1373-1389.

(40) Chen, S.; Xiong, C.; Liu, H.; Wan, Q.; Hou, J.; He, Q.; BaduTawiah, A.; Nie, Z. Mass Spectrometry Imaging Reveals the Sub-Organ Distribution of Carbon Nanomaterials. Nat. Nanotechnol. 2015, 10, 176-182.

(41) Copeland, S.; Warren, H. S.; Lowry, S. F.; Calvano, S. E.; Remick, D. Acute Inflammatory Response To Endotoxin In Mice and Humans. Clin. Diagn. Lab. Immunol. 2005, 12, 60-67.

(42) Sasidharan, A.; Swaroop, S.; Koduri, C. K.; Girish, C. M.; Chandran, P.; Panchakarla, L. S.; Somasundaram, V. H.; Gowd, G. S.; Nair, S.; Koyakutty, M. Comparative In Vivo Toxicity, Organ Biodistribution and Immune Response of Pristine, Carboxylated and Pegylated Few-Layer Graphene Sheets In Swiss Albino Mice: A Three Month Study. Carbon 2015, 95, 511-524.

(43) Qu, G.; Wang, X.; Liu, Q.; Liu, R.; Yin, N.; Ma, J.; Chen, L.; He, J.; Liu, S.; Jiang, G. The Ex Vivo and In Vivo Biological Performances of Graphene Oxide and the Impact of Surfactant On Graphene Oxide's Biocompatibility. J. Environ. Sci. 2013, 25, 873-881.

(44) Yang, K.; Gong, H.; Shi, X.; Wan, J.; Zhang, Y.; Liu, Z. In Vivo Biodistribution and Toxicology of Functionalized Nano-Graphene Oxide in Mice After Oral and Intraperitoneal Administration. Biomaterials 2013, 34, 2787-2795.

(45) Wang, X.; Podila, R.; Shannahan, J. H.; Rao, A. M.; Brown, J. M. Intravenously Delivered Graphene Nanosheets and Multiwalled Carbon Nanotubes Induce Site-Specific Th2 Inflammatory Responses Via the Il-33/St2 Axis. Int. J. Nanomed. 2013, 8, 1733-1748.

(46) Li, B.; Yang, J.; Huang, Q.; Zhang, Y.; Peng, C.; Zhang, Y.; He, Y.; Shi, J.; Li, W.; Hu, J.; Fan, C. Biodistribution and Pulmonary Toxicity of Intratracheally Instilled Graphene Oxide In Mice. NPG Asia Mater. 2013, 5, No. e44.

(47) Suttie, A. W. Histopathology of the Spleen. Toxicol. Pathol. 2006, 34, 466-503.

(48) Masuda, T.; Satodate, R.; Tsuruga, K.; Kasai, T. Quantitative Assessment of a Change of Hemosiderin Deposition With Age In Splenic Compartments of Rats. Tohoku J. Exp. Med. 1993, 170, 169179.

(49) Wen, K. P.; Chen, Y. C.; Chuang, C. H.; Chang, H. Y.; Lee, C. Y.; Tai, N. H. Accumulation and Toxicity of Intravenously-Injected Functionalized Graphene Oxide In Mice. J. Appl. Toxicol. 2015, 35, $1211-1218$.

(50) Sharron, M.; Hoptay, C. E.; Wiles, A. A.; Garvin, L. M.; Geha, M.; Benton, A. S.; Nagaraju, K.; Freishtat, R. J. Platelets Induce Apoptosis During Sepsis In a Contact-Dependent Manner That Is Inhibited By GPIIB/IIIA Bockade. PLoS One 2012, 7, No. e41549.

(51) Figgett, W. A.; Fairfax, K.; Vincent, F. B.; Le Page, M. A.; Katik, I.; Deliyanti, D.; Quah, P. S.; Verma, P.; Grumont, R.; Gerondakis, S.; Hertzog, P.; O'Reilly, L. A.; Strasser, A.; Mackay, F. The TACI Receptor Regulates T-Cell-Independent Marginal Zone B Cell Responses Through Innate Activation-Induced Cell Death. Immunity 2013, 39, 573-583.

(52) Schnitzer, B.; Rucknagel, D. L.; Spencer, H. H.; Aikawa, M. Erythrocytes: Pits and Vacuoles as Seen With Transmission and Scanning Electron Microscopy. Science 1971, 173, 251-252.

(53) Holroyde, C. P.; Gardner, F. H. Acquisition of Autophagic Vacuoles By Human Erythrocytes. Physiological Role of the Spleen. Blood 1970, 36, 566-575.

(54) Dameshek, W. Hypersplenism. Bull. N. Y. Acad. Med. 1955, 31, $113-136$.

(55) William, B. M.; Corazza, G. R. Hyposplenism: A Comprehensive Review. Part I: Basic Concepts and Causes. Hematology 2007, 12, 1-13.

(56) Doll, D. C.; List, A. F.; Yarbro, J. W. Functional Hyposplenism. South. Med. J. 1987, 80, 999-1006.

(57) Russell, E. S.; Neufeld, E. F.; Higgins, C. T. Comparison of Normal Blood Picture of Young Adults From 18 Inbred Strains of Mice. Exp. Biol. Med. 1951, 78, 761-766.
(58) Gottlieb, Y.; Topaz, O.; Cohen, L. A.; Yakov, L. D.; Haber, T.; Morgenstern, A.; Weiss, A.; Chait Berman, K.; Fibach, E.; MeyronHoltz, E. G. Physiologically Aged Red Blood Cells Undergo Erythrophagocytosis In Vivo But Not In Vitro. Haematologica 2012, 97, 994-1002.

(59) Knutson, M.; Wessling-Resnick, M. Iron Metabolism In the Reticuloendothelial System. Crit. Rev. Biochem. Mol. Biol. 2003, 38, 6188.

(60) Kohyama, M.; Ise, W.; Edelson, B. T.; Wilker, P. R.; Hildner, K.; Mejia, C.; Frazier, W. A.; Murphy, T. L.; Murphy, K. M. Role for Spi-C In the Development of Red Pulp Macrophages and Splenic Iron Homeostasis. Nature 2009, 457, 318-321.

(61) Franken, L.; Klein, M.; Spasova, M.; Elsukova, A.; Wiedwald, U.; Welz, M.; Knolle, P.; Farle, M.; Limmer, A.; Kurts, C. Splenic Red Pulp Macrophages are Intrinsically Superparamagnetic and Contaminate Magnetic Cell Isolates. Sci. Rep. 2015, 5, 12940.

(62) Nolan, Y.; Vereker, E.; Lynch, A. M.; Lynch, M. A. Evidence That Lipopolysaccharide-Induced Cell Death Is Mediated By Accumulation of Reactive Oxygen Species and Activation of P38 In Rat Cortex and Hippocampus. Exp. Neurol. 2003, 184, 794-804.

(63) Wu, H.; Shi, H.; Wang, Y.; Jia, X.; Tang, C.; Zhang, J.; Yang, S. Hyaluronic Acid Conjugated Graphene Oxide for Targeted Drug Delivery. Carbon 2014, 69, 379-389.

(64) Kanakia, S.; Toussaint, J. D.; Mullick Chowdhury, S.; Tembulkar, T.; Lee, S.; Jiang, Y. P.; Lin, R. Z.; Shroyer, K. R.; Moore, W.; Sitharaman, B. Dose Ranging, Expanded Acute Toxicity and Safety Pharmacology Studies for Intravenously Administered Functionalized Graphene Nanoparticle Formulations. Biomaterials 2014, 35, 70227031.

(65) Nurunnabi, M.; Khatun, Z.; Huh, K. M.; Park, S. Y.; Lee, D. Y.; Cho, K. J.; Lee, Y.-k. In Vivo Biodistribution and Toxicology of Carboxylated Graphene Quantum Dots. ACS Nano 2013, 7, 68586867.

(66) Chong, Y.; Ma, Y.; Shen, H.; Tu, X.; Zhou, X.; Xu, J.; Dai, J.; Fan, S.; Zhang, Z. The In Vitro and In Vivo Toxicity of Graphene Quantum Dots. Biomaterials 2014, 35, 5041-5048.

(67) Zhang, D.; Zhang, Z.; Liu, Y.; Chu, M.; Yang, C.; Li, W.; Shao, Y.; Yue, Y.; Xu, R. The Short- and Long-Term Effects of Orally Administered High-Dose Reduced Graphene Oxide Nanosheets On Mouse Behaviors. Biomaterials 2015, 68, 100-113.

(68) de Porto, A. P. N. A.; Lammers, A. J. J.; Bennink, R. J.; ten Berge, I. J. M.; Speelman, P.; Hoekstra, J. B. L. Assessment of Splenic Function. Eur. J. Clin. Microbiol. Infect. Dis. 2010, 29, 1465-1473.

(69) Langeveld, M.; Gamadia, L. E.; ten Berge, I. J. T-lymphocyte Subset Distribution In Human Spleen. Eur. J. Clin. Invest. 2006, 36, $250-256$.

(70) Orecchioni, M.; Jasim, D. A.; Pescatori, M.; Manetti, R.; Fozza, C.; Sgarrella, F.; Bedognetti, D.; Bianco, A.; Kostarelos, K.; Delogu, L. G. Molecular and Genomic Impact of Large and Small Lateral Dimension Graphene Oxide Sheets On Human Immune Cells From Healthy Donors. Adv. Healthcare Mater. 2016, 5, 276-287.

(71) Sydlik, S. A.; Jhunjhunwala, S.; Webber, M. J.; Anderson, D. G.; Langer, R. In Vivo Compatibility of Graphene Oxide With Differing Oxidation States. ACS Nano 2015, 9, 3866-3874.

(72) Assoian, R. K.; Fleurdelys, B. E.; Stevenson, H. C.; Miller, P. J.; Madtes, D. K.; Raines, E. W.; Ross, R.; Sporn, M. B. Expression and Secretion of Type Beta Transforming Growth Factor By Activated Human Macrophages. Proc. Natl. Acad. Sci. U. S. A. 1987, 84, 60206024.

(73) Said, E. A.; Dupuy, F. P.; Trautmann, L.; Zhang, Y.; Shi, Y.; ElFar, M.; Hill, B. J.; Noto, A.; Ancuta, P.; Peretz, Y.; Fonseca, S. G.; Van Grevenynghe, J.; Boulassel, M. R.; Bruneau, J.; Shoukry, N. H.; Routy, J.-P.; Douek, D. C.; Haddad, E. K.; Sekaly, R.-P. Programmed Death-1Induced Interleukin-10 Production By Monocytes Impairs CD4+ T Cell Activation During HIV Infection. Nat. Med. 2010, 16, 452-459.

(74) Lopez-Castejon, G.; Brough, D. Understanding the Mechanism of IL-1Beta Secretion. Cytokine Growth Factor Rev. 2011, 22, 189-195. 
(75) Malstrom, C.; James, S. Inhibition of Murine Splenic and Mucosal Lymphocyte Function By Enteric Bacterial Products. Infect. Immun. 1998, 66, 3120-3127.

(76) Ertel, W.; Kremer, J. P.; Kenney, J.; Steckholzer, U.; Jarrar, D.; Trentz, O.; Schildberg, F. W. Downregulation of Proinflammatory Cytokine Release In Whole Blood From Septic Patients. Blood 1995, 85, 1341-1347.

(77) Trinschek, B.; Luessi, F.; Haas, J.; Wildemann, B.; Zipp, F.; Wiendl, H.; Becker, C.; Jonuleit, H. Kinetics of IL-6 Production Defines $\mathrm{T}$ Effector Cell Responsiveness To Regulatory T Cells In Multiple Sclerosis. PLoS One 2013, 8, No. e77634.

(78) Seiler, P.; Aichele, P.; Odermatt, B.; Hengartner, H.; Zinkernagel, R. M.; Schwendener, R. A. Crucial Role of Marginal Zone Macrophages and Marginal Zone Metallophils In the Clearance of Lymphocytic Choriomeningitis Virus Infection. Eur. J. Immunol. 1997, 27, 26262633.

(79) Gherman, C.; Tudor, M. C.; Constantin, B.; Flaviu, T.; Stefan, R.; Maria, B.; Chira, S.; Braicu, C.; Pop, L.; Petric, R. C.; Berindan-Neagoe, I. Pharmacokinetics Evaluation of Carbon Nanotubes Using FTIR Analysis and Histological Analysis. J. Nanosci. Nanotechnol. 2015, 15, 2865-2869.

(80) Birjandi, S. Z.; Ippolito, J. A.; Ramadorai, A. K.; Witte, P. L. Alterations in Marginal Zone Macrophages and Marginal Zone B Cells In Old Mice. J. Immunol. 2011, 186, 3441-3451.

(81) Schultz, Z. D.; Stranick, S. J.; Levin, I. W. Tip Enhanced Raman Spectroscopy and Imaging: An Apical Illumination Geometry. Appl. Spectrosc. 2008, 62, 1173-1179.

(82) Anselmo, A. C.; Gupta, V.; Zern, B. J.; Pan, D.; Zakrewsky, M.; Muzykantov, V.; Mitragotri, S. Delivering Nanoparticles To Lungs While Avoiding Liver and Spleen Through Adsorption On Red Blood Cells. ACS Nano 2013, 7, 11129-11137.

(83) Wang, J.; Ma, H.; Boor, P. J.; Ramanujam, V. M. S.; Ansari, G. A. S.; Khan, M. F. Up-Regulation of Heme Oxygenase-1 in Rat Spleen After Aniline Exposure. Free Radical Biol. Med. 2010, 48, 513-518.

(84) Ferrari, A. C.; Robertson, J. Interpretation of Raman Spectra of Disordered and Amorphous Carbon. Phys. Rev. B: Condens. Matter Mater. Phys. 2000, 61, 14095-14107.

(85) Thomsen, C.; Reich, S. Double Resonant Raman Scattering In Graphite. Phys. Rev. Lett. 2000, 85, 5214-5217.

(86) Ali-Boucetta, H.; Bitounis, D.; Raveendran-Nair, R.; Servant, A.; Van den Bossche, J.; Kostarelos, K. Graphene Oxide: Purified Graphene Oxide Dispersions Lack In Vitro Cytotoxicity and In Vivo Pathogenicity. Adv. Healthcare Mater. 2013, 2, 433-441.

(87) Tuinstra, F.; Koenig, J. L. Raman Spectrum of Graphite. J. Chem. Phys. 1970, 53, 1126-1130.

(88) Chen, X.; Chen, B. Direct Observation, Molecular Structure, and Location of Oxidation Debris On Graphene Oxide Nanosheets. Environ. Sci. Technol. 2016, 50, 8568-8577.

(89) Lucchese, M. M.; Stavale, F.; Ferreira, E. H. M.; Vilani, C.; Moutinho, M. V. O.; Capaz, R. B.; Achete, C. A.; Jorio, A. Quantifying Ion-Induced Defects and Raman Relaxation Length In Graphene. Carbon 2010, 48, 1592-1597.

(90) Mukherjee, S. P.; Gliga, A. R.; Lazzaretto, B.; Brandner, B.; Fielden, M.; Vogt, C.; Newman, L.; Rodrigues, A. F.; Shao, W.; Fournier, P. M.; Toprak, M. S.; Star, A.; Kostarelos, K.; Bhattacharya, K.; Fadeel, B. Graphene Oxide Is Degraded By Neutrophils and the Degradation Products are Non-Genotoxic. Nanoscale 2018, 10, 11801188.

(91) Smith, B. W.; Luzzi, D. E. Electron Irradiation Effects In Single Wall Carbon Nanotubes. J. Appl. Phys. 2001, 90, 3509-3515.

(92) Elgrabli, D.; Dachraoui, W.; Ménard-Moyon, C.; Liu, X. J.; Bégin, D.; Bégin-Colin, S.; Bianco, A.; Gazeau, F.; Alloyeau, D. Carbon Nanotube Degradation In Macrophages: Live Nanoscale Monitoring and Understanding of Biological Pathway. ACS Nano 2015, 9, 1011310124.

(93) Yang, M.; Zhang, M. Biodegradation of Carbon Nanotubes By Macrophages. Front. Mater. 2019, 6, DOI: 10.3389/fmats.2019.00225.
(94) Hirayama, D.; Iida, T.; Nakase, H. The Phagocytic Function of Macrophage-Enforcing Innate Immunity and Tissue Homeostasis. Int. J. Mol. Sci. 2018, 19, 92.

(95) Kagan, V. E.; Konduru, N. V.; Feng, W.; Allen, B. L.; Conroy, J.; Volkov, Y.; Vlasova, I. I.; Belikova, N. A.; Yanamala, N.; Kapralov, A.; Tyurina, Y. Y.; Shi, J.; Kisin, E. R.; Murray, A. R.; Franks, J.; Stolz, D.; Gou, P.; Klein-Seetharaman, J.; Fadeel, B.; Star, A.; et al. Carbon Nanotubes Degraded By Neutrophil Myeloperoxidase Induce Less Pulmonary Inflammation. Nat. Nanotechnol. 2010, 5, 354-359.

(96) Osmond-McLeod, M. J.; Poland, C. A.; Murphy, F.; Waddington, L.; Morris, H.; Hawkins, S. C.; Clark, S.; Aitken, R.; McCall, M. J.; Donaldson, K. Durability and Inflammogenic Impact of Carbon Nanotubes Compared With Asbestos Fibres. Part. Fibre Toxicol. 2011, 8,15 .

(97) Sahadev, N.; Anappara, A. A. Enhanced Photothermal Effect In Reduced Graphene Oxide In Solid-State. J. Appl. Phys. 2017, 122, 185103.

(98) Wu, J.; Li, Z.; Li, Y.; Pettitt, A.; Zhou, F. Photothermal Effects of Reduced Graphene Oxide On Pancreatic Cancer Technol. Cancer Res. Treat. 2018, 17 DOI: $10.1177 / 1533034618768637$.

(99) Russier, J.; Oudjedi, L.; Piponnier, M.; Bussy, C.; Prato, M.; Kostarelos, K.; Lounis, B.; Bianco, A.; Cognet, L. Direct Visualization of Carbon Nanotube Degradation In Primary Cells By Photothermal Imaging. Nanoscale 2017, 9, 4642-4645.

(100) Lee, J.; Lilly, G. D.; Doty, R. C.; Podsiadlo, P.; Kotov, N. A. In Vitro Toxicity Testing of Nanoparticles In 3D Cell Culture. Small 2009, 5, 1213-1221.

(101) Nunes, A. S.; Barros, A. S.; Costa, E. C.; Moreira, A. F.; Correia, I. J. 3D Tumor Spheroids as In Vitro Models to Mimic In Vivo Human Solid Tumors Resistance To Therapeutic Drugs. Biotechnol. Bioeng. 2019, 116, 206-226.

(102) Curcio, A.; Van de Walle, A.; Serrano, A.; Preveral, S.; Péchoux, C.; Pignol, D.; Menguy, N.; Lefevre, C. T.; Espinosa, A.; Wilhelm, C. Transformation Cycle of Magnetosomes In Human Stem Cells: From Degradation To Biosynthesis of Magnetic Nanoparticles Anew. ACS Nano 2020, 14, 1406-1417.

(103) Lammers, T.; Kiessling, F.; Hennink, W. E.; Storm, G. Drug Targeting To Tumors: Principles, Pitfalls and (Pre-) Clinical Progress. J. Controlled Release 2012, 161, 175-187.

(104) Lipson, R. L.; Bayrd, E. D.; Watkins, C. H. The Postsplenectomy Blood Picture. Am. J. Clin. Pathol. 1959, 32, 526-532.

\section{NOTE ADDED AFTER ASAP PUBLICATION}

This paper was published ASAP on July 28, 2020. The caption to Figure 5 was corrected. The revised paper was reposted on August 11, 2020. 